\title{
Lithium rescues synaptic plasticity and memory in Down syndrome mice
}

\author{
Andrea Contestabile, Barbara Greco, Diego Ghezzi, \\ Valter Tucci, Fabio Benfenati, and Laura Gasparini
}

Department of Neuroscience and Brain Technologies, Istituto Italiano di Tecnologia, Genova, Italy.

\begin{abstract}
Down syndrome (DS) patients exhibit abnormalities of hippocampal-dependent explicit memory, a feature that is replicated in relevant mouse models of the disease. Adult hippocampal neurogenesis, which is impaired in DS and other neuropsychiatric diseases, plays a key role in hippocampal circuit plasticity and has been implicated in learning and memory. However, it remains unknown whether increasing adult neurogenesis improves hippocampal plasticity and behavioral performance in the multifactorial context of DS. We report that, in the Ts65Dn mouse model of DS, chronic administration of lithium, a clinically used mood stabilizer, promoted the proliferation of neuronal precursor cells through the pharmacological activation of the Wnt/ $\beta$-catenin pathway and restored adult neurogenesis in the hippocampal dentate gyrus (DG) to physiological levels. The restoration of adult neurogenesis completely rescued the synaptic plasticity of newborn neurons in the DG and led to the full recovery of behavioral performance in fear conditioning, object location, and novel object recognition tests. These findings indicate that reestablishing a functional population of hippocampal newborn neurons in adult DS mice rescues hippocampal plasticity and memory and implicate adult neurogenesis as a promising therapeutic target to alleviate cognitive deficits in DS patients.
\end{abstract}

\section{Introduction}

In mammals, new neurons are produced throughout life in 2 neurogenic niches, i.e., the subventricular zone (SVZ) and the hippocampal dentate gyrus (DG). The DG plays a pivotal role in cognition. Experimental and computational studies indicate that newborn neurons in the DG are essential for hippocampal function due to the enhanced synaptic plasticity properties of these cells (i.e., increased intrinsic excitability and reduced sensitivity to GABAergic inhibition) compared with those of preexisting mature dentate granule cells (DGCs) (1-8). Given these peculiar electrophysiological features, it has been proposed that maturing newborn neurons distinctively contribute to information processing in the DG and participate in the expression of specific forms of hippocampal-dependent learning and memory in rodents, including contextual learning $(7,9,10)$, cognitive flexibility (11), and pattern separation $(12,13)$.

The impairment of adult neurogenesis has been observed in a variety of models relevant to neuropsychiatric diseases, such as major depression, schizophrenia, and Alzheimer disease (14-18), and neurodevelopmental disorders, including fragile $\mathrm{X}$ and Down syndrome (DS) $(19,20)$. To date, there is no direct evidence supporting a role for adult neurogenesis in specific diseases. However, recent data in epileptic patients undergoing en bloc hippocampus resection indicate that low proliferation and differentiation capacities of adult hippocampal stem cells correlate with memory dysfunction (21). Yet adult neurogenesis is highly sensitive to environmental stimuli, including environmental enrichment (22) and exogenous molecules (23). Thus, adult neurogenesis represents an attractive, though unexplored, opportunity to develop therapies for disease-associated cognitive impairment and might be particularly relevant for neurodevelopmental diseases with complex genetic etiologies, such as DS.

Conflict of interest: The authors have declared that no conflict of interest exists. Citation for this article: J Clin Invest. 2013;123(1):348-361. doi:10.1172/JCI64650.
DS results from the trisomy of chromosome 21 in humans and is the leading cause of genetically defined intellectual disability. In the DS brain, suboptimal network architecture and altered synaptic communication through neurodevelopmental impairment represent key determinants of intellectual disabilities in DS, which involve several cognitive domains, such as language, verbal and spatial learning, and memory (reviewed in ref. 24). Both hippocampal and prefrontal-related functions appear defective in DS subjects (25-27), although these defects apparently manifest at different ages. Hippocampal dysfunction occurs in DS children and adolescents, with impairment of spatial associative memory as detected with the CANTAB Paired Associates Learning test and sparing of the prefrontal-mediated reference memory (25).

Over the past decades, several trisomic DS mouse models have been generated, recapitulating essential genetic and cognitive deficits of human DS (reviewed in ref. 24). The results of studies conducted in such models have suggested that cognitive dysfunction is not due to gross neuroanatomical abnormalities, but rather derives from both changes in synaptic connectivity (e.g., excitation/ inhibition imbalance) and altered developmental neurogenesis during embryogenesis and the early postnatal period (28-33). The widely used Ts65Dn mouse is a relevant model of DS, reproducing several phenotypic abnormalities of the human disease (34). Studies using this model have reported that neurogenesis is reduced in both the adult DG and SVZ, and the stimulation of neurogenesis using drugs, such as fluoxetine (35) or lithium (36), induces the proliferation of neural precursor cells (NPCs) and the expression of discrete molecular markers of newborn neurons in the DG and SVZ. However, the subsequent integration of adult-generated neurons with the DS hippocampal circuit remains unexplored. Moreover, it is still unclear whether impairment of adult neurogenesis in DS is a primary event or a neuroadaptive response to complex pathological mechanisms. Nevertheless, independently of its origin, one fundamental question of potential therapeutic relevance is whether increasing adult neurogenesis improves hippocampal 
plasticity and behavioral performance in the multifactorial context of DS. In this study, we used 5- to 6-month-old adult Ts65Dn mice to investigate this critical point. To enhance neurogenesis, the mice were treated with lithium, a mood-stabilizing agent that specifically stimulates the proliferation of NPCs through the Wnt pathway $(37,38)$ without affecting gliogenesis (39).

The results showed that DG adult neurogenesis could be restored to physiological levels after 4 weeks of lithium administration in the Ts65Dn trisomic mouse, resulting in the full recovery of DG synaptic plasticity and hippocampal-dependent cognitive functions, as determined using contextual fear conditioning (CFC), object location (OL), and novel object recognition (NOR) tasks. We also demonstrated that lithium treatment increased neurogenesis by stimulating NPC proliferation via the Wnt/ $\beta$-catenin pathway without affecting fate determination and newborn neuron survival.

\section{Results}

Adult neurogenesis in the DG of Ts65Dn mice is restored to physiological levels using lithium. We initially examined the number of newborn neurons in the Ts65Dn DG and established a protocol for promoting adult neurogenesis through the administration of lithium, a widely used mood stabilizer that stimulates the proliferation of NPCs via Wnt signaling $(37,38)$. To visualize newborn neurons, we evaluated the early neuronal marker doublecortin (DCX), which is expressed from the late precursor stage until 3 to 4 weeks after newly generated neurons become postmitotic (Figure $1 \mathrm{~A}$ and ref. 40). We observed that the number of maturing newborn neurons expressing DCX was reduced by $60 \%$ in the DG of untreated Ts $65 \mathrm{Dn}$ mice (Figure 1, B and $\mathrm{C})$. Four weeks of treatment with lithium $\left(\mathrm{Li}_{2} \mathrm{CO}_{3}, 2.4 \mathrm{~g} / \mathrm{kg}\right.$ of chow) fully restored the number of $\mathrm{DCX}^{+}$neurons in the DG of trisomic mice to levels comparable with those of untreated WT littermates (Figure 1, B and C). The number of $\mathrm{DCX}^{+}$newborn neurons was also augmented in the lithium-treated WT mice. However, the lithium-induced increase was much higher in trisomic mice (174\%) than in the WT littermates (50\%). Similar results were obtained when neurogenesis was evaluated using the neuronal marker calretinin (CR), which is transiently expressed in adult-born neurons until 1 to 2 weeks after their birth (Figure $1 \mathrm{~A}$ and ref. 40 ). The number of $\mathrm{CR}^{+}$neurons was reduced by $45 \%$ in the DG of untreated Ts65Dn mice and increased in both WT mice (53\%) and trisomic littermates (173\%) after lithium treatment (Figure 1, D and E).

Enhancing adult neurogenesis rescues DG synaptic plasticity in Ts65Dn mice. Next, we examined whether the reduced neurogenesis in Ts65Dn mice was associated with impaired DG synaptic plasticity (29) and whether lithium-rescued newborn neurons were physiologically functional. It has been demonstrated that, at 3 to 4 weeks after becoming postmitotic, maturing newborn neurons exhibit unique electrophysiological features, including increased excitability, enhanced synaptic plasticity, insensitivity to GABA inhibition, and a lower threshold for the induction of long-term potentiation (LTP) than mature DGCs $(2-4,6,8)$. Neurogenesis-dependent LTP relies on the activation of glutamate receptors containing the NR2B subunit and can be induced in the DG in the presence of intact GABAergic inhibition. Conversely, the LTP of preexisting mature DGCs can only be induced when local GABAergic inhibition is blocked $(1,5,7,11,12)$.

We observed that while basal synaptic transmission and shortterm plasticity were normal (Supplemental Figure 1, A and B; supplemental material available online with this article; doi:10.1172/
JCI64650DS1), high-frequency stimulation of the medial perforant path (MPP) failed to elicit LTP in artificial cerebrospinal fluid (ACSF-LTP) in Ts65Dn hippocampal slices in the absence of $\mathrm{GABA}_{\mathrm{A}}$ receptor blockers (Figure 2, B and F). Remarkably, 4 weeks of lithium treatment reestablished ACSF-LTP in Ts65Dn mice to levels indistinguishable from those in untreated WT littermates (Figure 2, C and F). The bath application of the NR2B antagonist Ro25-6981 blocked potentiation in slices from lithium-fed Ts65Dn mice and untreated or lithium-treated WT littermates, thus confirming the specific induction of newborn neuron-dependent ACSF-LTP (Figure 2, D and F, and Supplemental Figure 1, $\mathrm{C}-\mathrm{E})$. Conversely, high-frequency stimulation in the presence of the $\mathrm{GABA}_{\mathrm{A}}$ receptor blocker picrotoxin (PTX) elicited comparable potentiation (PTX-LTP) in hippocampal slices from both treated and untreated WT and Ts65Dn mice (Supplemental Figure 1, $\mathrm{F}-\mathrm{H}$ ), indicating that synaptic plasticity of mature DGCs is unaffected in Ts65Dn mice and is not modulated by lithium.

Functional newborn neurons are necessary for LTP recovery. We evaluated whether the effects of lithium on synaptic potentiation were dependent on functional neurogenesis. Thus, we examined LTP after a 1-week administration of lithium, which is sufficient to develop therapeutic concentrations of lithium in the mouse (Supplemental Figure 2) and rat brain (41), but inadequate for newly generated neurons to integrate into the hippocampal circuit (Figure 1A and refs. 2, 4). Indeed, the shortterm lithium treatment failed to restore potentiation in Ts65Dn mice and did not change LTP in WT littermates (Figure 2, E and F), highlighting the requirement of functional neurogenesis for synaptic potentiation.

We further investigated whether newborn neurons were necessary for the lithium-mediated rescue of LTP in the DG of Ts65Dn mice through the administration of a low dose of the cytostatic drug temozolomide (TMZ), which has been shown to block adult neurogenesis, neurogenesis-dependent ACSF-LTP, and spatial memory without detectable side effects $(11,42)$. Initial experiments in WT mice confirmed that TMZ treatment inhibited neurogenesis in a concentration-dependent manner, reducing the number of $\mathrm{DCX}^{+}$ neurons to approximately $18 \%$ and $48 \%$ at 12.5 and $25 \mathrm{mg} / \mathrm{kg}$, respectively (Supplemental Figure 3). Notably, only a high dose of TMZ inhibited the induction of neurogenesis-dependent ACSF-LTP (Supplemental Figure 3, C and D), while the low dose was ineffective on synaptic plasticity. Consistent with previous results (11), a $25 \mathrm{mg} / \mathrm{kg}$ TMZ treatment did not alter the LTP of mature DG neurons (PTX-LTP) or affect potentiation at Shaffer collateral-CA1 synapses (CA3-CA1 LTP) (Supplemental Figure 3, E-H). This finding indicates that, at this dose, TMZ specifically impairs neurogenesis-dependent LTP without affecting the functional properties of other hippocampal neuronal populations in WT mice, consistent with the preserved density of $\mathrm{NeuN}^{+}$neurons in the CA1 and CA3 regions of the hippocampus (Supplemental Figure 4). Similarly, in Ts65Dn mice, TMZ further reduced the number of $\mathrm{DCX}^{+}$newborn neurons without changing the density of $\mathrm{NeuN}^{+}$neurons, indicating a selective effect on adult neurogenesis.

When coadministered with lithium, TMZ reduced the number of $\mathrm{DCX}^{+}$newborn neurons in both Ts65Dn mice and WT littermates, completely blocking the effects of lithium. Indeed, the number of newborn neurons was reduced by $59 \%$ in Ts 65 Dn mice and by $64 \%$ in WT littermates treated with both TMZ and lithium compared with mice of the same genotype treated with lithium alone (Figure 3A). Consistently, ACSF-LTP was abolished in both 
A

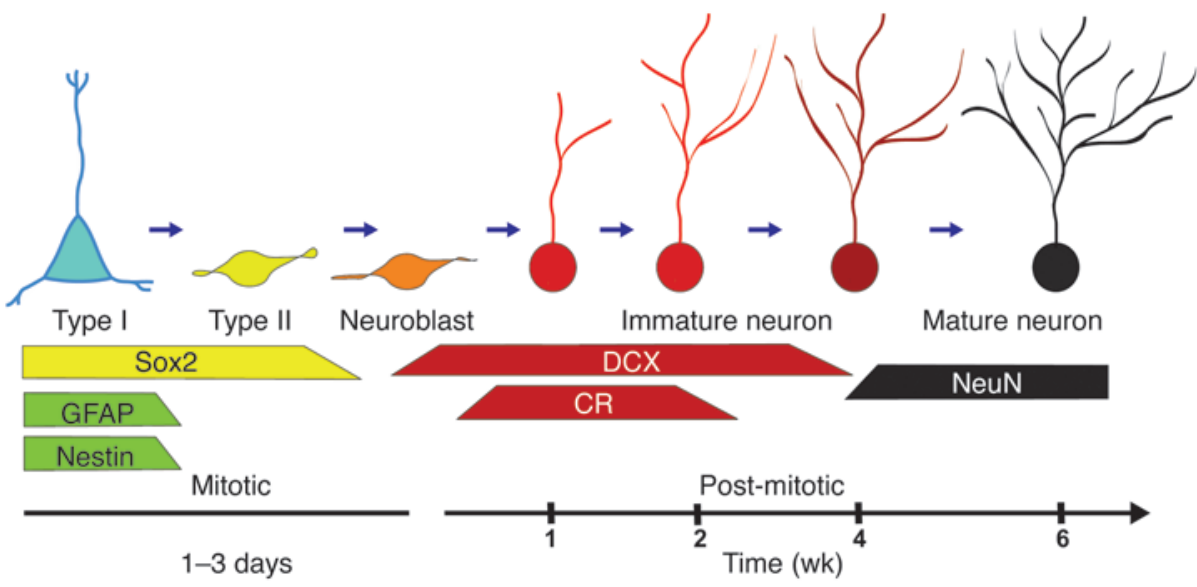

B

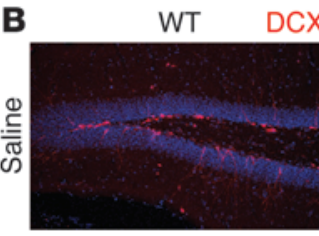

XX Nuclei Ts65Dn
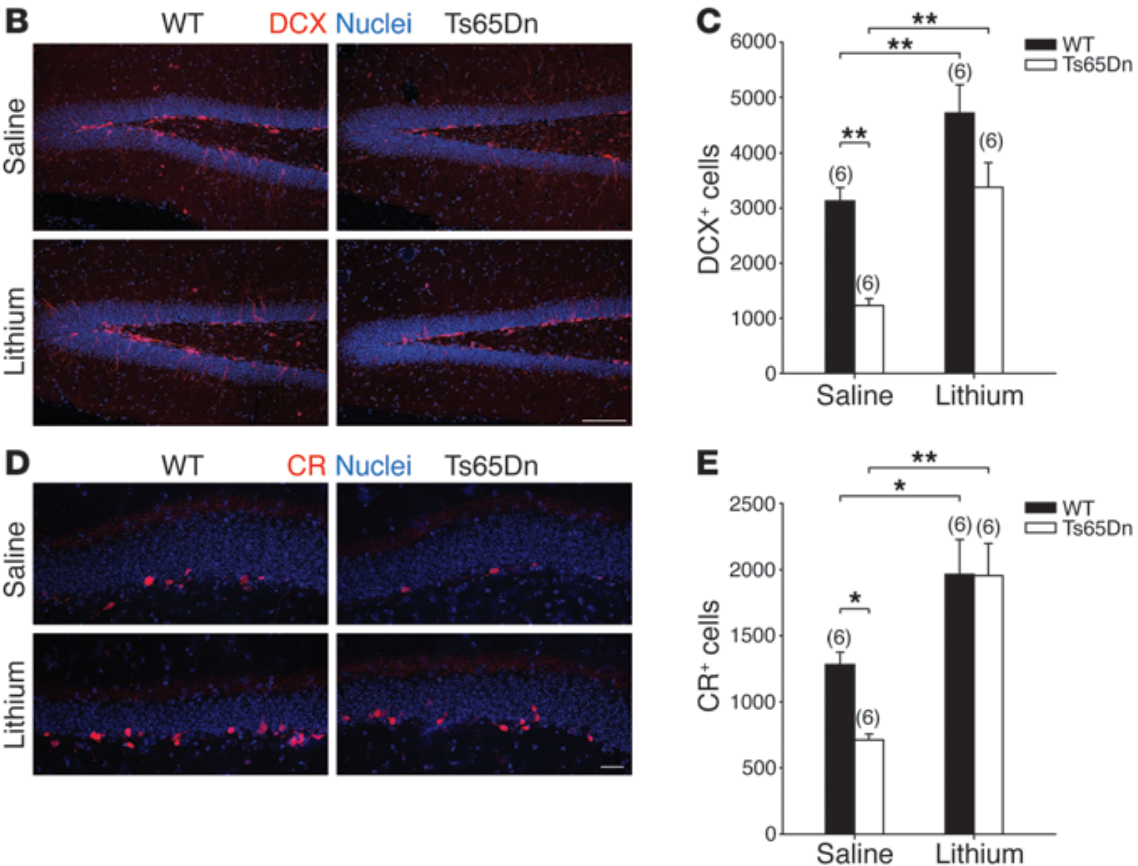

Figure 1

Lithium restored the number of newborn neurons in DG of adult Ts65Dn mice. (A) Expression of molecular markers during adult DG neurogenesis. During the mitotic phase, 2 types of progenitors proliferate in the SGZ of the DG: RGL progenitors (type I cells, expressing Nestin, GFAP, and Sox2) and amplifying progenitors (type II cells, expressing Sox2 only). Before becoming postmitotic, the progenitors undergo a short intermediate stage (neuroblasts), commit to the neuronal fate, and begin expressing DCX. In the postmitotic phase, DCX-positive newborn neurons derived from neuroblasts undergo a morphological and physiological maturing process with the sequential expression of $\mathrm{CR}$ and NeuN upon final maturation. (B-E) Five- to six-month-old Ts65Dn and WT mice were treated with lithium or saline for 4 weeks, and the number of newborn neurons was evaluated through immunohistochemistry for DCX or CR (red) and counterstained with Hoechst-33342 (blue). (B) Immunoreactivity and (C) number of DCX+ newborn neurons in saline- or lithium-treated Ts65Dn and WT mice. 2-way ANOVA: genotype $\left(F_{1,20}=19.285, P<0.001\right)$, treatment $\left(F_{1,20}=25.570, P<0.001\right)$, genotype $\times$ treatment $\left(F_{1,20}=0.584, P=0.454\right)$. (D) Immunoreactivity and $(E)$ number of $C R^{+}$newborn neurons in DG of saline- or lithium-treated Ts65Dn and WT mice. 2-way ANOVA: genotype $\left(F_{1,20}=2.413, P=0.136\right)$, treatment $\left(F_{1,20}=26.602\right.$, $P<0.001)$, genotype $\times$ treatment $\left(F_{1,20}=2.247, P=0.149\right)$. Numbers in parentheses indicate the number of animals in each group. ${ }^{*} P<0.05$; ${ }^{* \star} P<0.01$, Tukey's post hoc test. Scale bars: $100 \mu \mathrm{m}(\mathbf{B}) ; 25 \mu \mathrm{m}(\mathbf{D})$.

WT and Ts65Dn mice treated with lithium and TMZ (Figure 3, B-D). Importantly, TMZ treatment did not affect DG basal synaptic transmission and short-term plasticity (Supplemental Figure 5, $\mathrm{A}$ and $\mathrm{B}$ ) or the LTP of mature dentate neurons (PTX-LTP) in both Ts65Dn and WT mice (Supplemental Figure 5, C-E), confirming the selective impairment of neurogenesis-dependent ACSF-LTP.
Overall, these data indicate that the effects of lithium depend on functional neurogenesis and that newborn neurons are required to fully rescue LTP in the DG of Ts65Dn mice.

Restoring adult neurogenesis specifically rescues hippocampaldependent long-term explicit memory in Ts65Dn mice. Ts65Dn mice exhibit learning and memory deficits in several tasks, including 
A
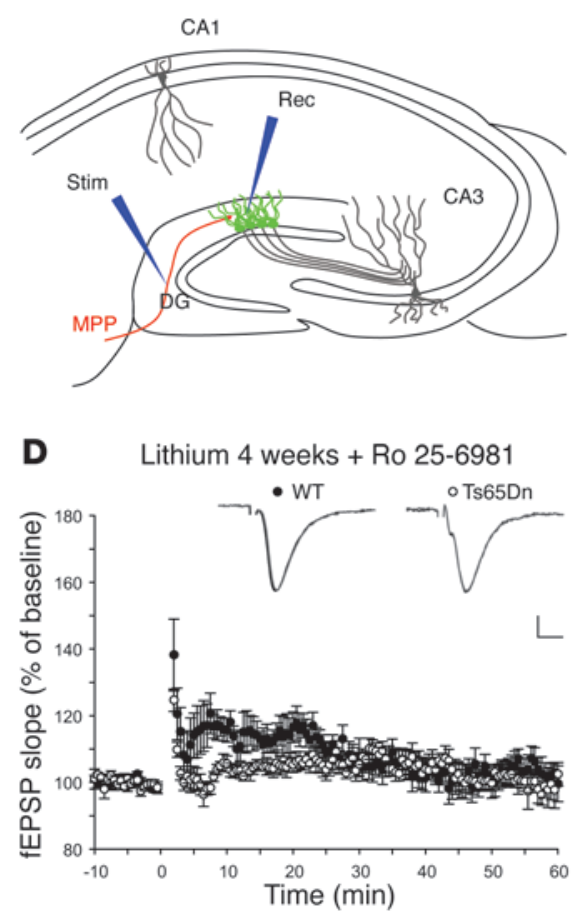

B

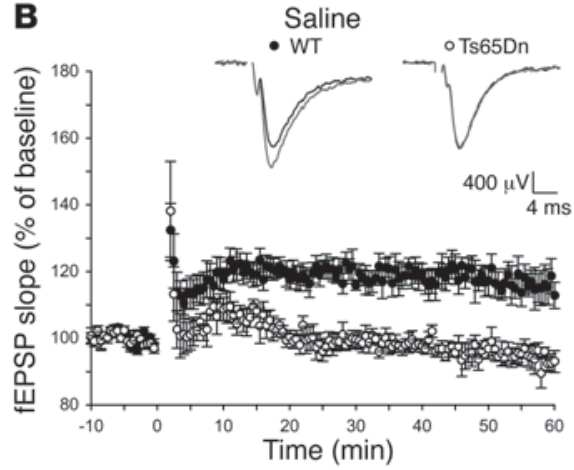

E

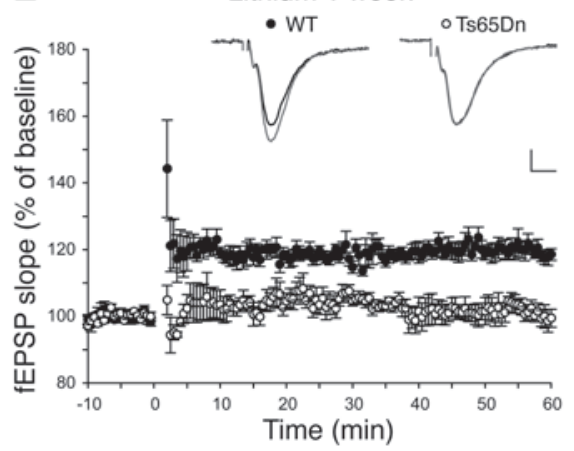

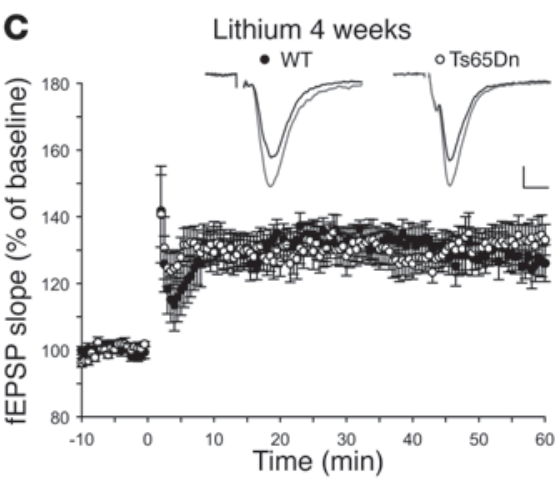

$\mathbf{F}$

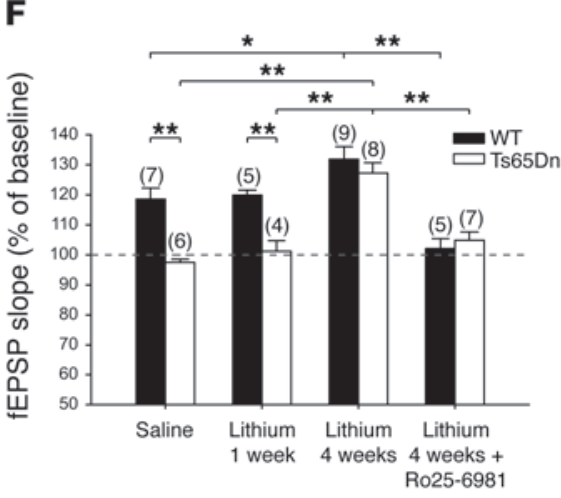

Figure 2

Restoration of adult neurogenesis rescued newborn neuron-dependent synaptic plasticity in the DG of Ts65Dn mice. fEPSPs in the DG medial molecular layer elicited through the stimulation of the MPP in ACSF were recorded in hippocampal slices obtained from Ts65Dn and WT mice fed with normal or lithium-containing diets for either 1 or 4 weeks. (A) Position of the stimulating and recording electrodes. (B) ACSF-LTP was induced in hippocampal slices from saline-treated WT $(P<0.01 \mathrm{vs}$. baseline) but not Ts65Dn mice $(P=0.190)$. (C) ACSF-LTP was restored in hippocampal slices of Ts65Dn mice $(P<0.01)$ and increased in slices from WT littermates $(P<0.01)$ after 4 weeks of lithium treatment. (D) ACSFLTP was inhibited through the specific NR2B antagonist Ro25-6981 (1.5 $\mu \mathrm{M})$ in hippocampal slices from WT $(P=0.469)$ and Ts65Dn $(P=0.091)$ mice treated with lithium for 4 weeks. (E) ACSF-LTP was induced in hippocampal slices of WT $(P<0.001)$ but not Ts65Dn $(P=0.802)$ mice treated with lithium for only 1 week. The insets in B-E show representative fEPSP traces recorded 5 minutes before (black) and 45 minutes after (gray) LTP induction. (F) Quantification of ACSF-LTP elicited in the DG of WT and Ts65Dn mice. Numbers in parentheses indicate the number of slices recorded for each experimental group. 2-way ANOVA: genotype $\left(F_{1,43}=16.721, P<0.001\right)$, treatment $\left(F_{3,43}=25.431, P<0.001\right)$, genotype $\times$ treatment $\left(F_{3,43}=4.996, P=0.005\right) .{ }^{\star} P<0.05 ;{ }^{* \star} P<0.01$, Tukey's post hoc test.

spatial memory (34), context learning (43), object discrimination (28), and working memory (28). Therefore, we determined whether rescuing adult neurogenesis and DG synaptic plasticity resulted in the recovery of hippocampus-dependent longterm explicit memory in Ts65Dn mice. We subjected the mice to a battery of 3 behavioral tasks (i.e., CFC, OL, and NOR) that depend on intact adult neurogenesis $(7,10,44-48)$. We observed that untreated Ts65Dn mice displayed a strong impairment in all 3 behavioral tests (Figure 4). This behavioral phenotype was independent of motor performance, as motor activity was not significantly different across genotypes and treatments (distance traveled, WT saline: $34.4 \pm 2.2 \mathrm{~m}, n=13$; Ts65Dn saline: $44.1 \pm 3.8 \mathrm{~m}, n=12$; WT lithium: $31.4 \pm 2.9 \mathrm{~m}, n=15$; Ts $65 \mathrm{Dn}$ lithium: $39.9 \pm 5.7 \mathrm{~m}, n=11$. 2-way ANOVA: genotype $\left[F_{1,47}=6.133\right.$, $P=0.017]$, treatment $\left[F_{1,47}=0.933, P=0.339\right]$, genotype $\times$ treatment $\left.\left[F_{1,47}=0.0249, P=0.875\right]\right)$.

Consistent with previous reports (43), untreated Ts65Dn mice showed a reduced freezing response in the CFC test, indicating impaired associative learning. Remarkably, a 4-week lithium administration fully restored contextual learning in Ts65Dn mice, which performed indistinguishably from WT littermates (Figure 4A).
To exclude the potential confounding effects on the freezing response (i.e., nonassociative freezing), the mice were exposed to a new context at 2 hours after the test. All groups of mice showed negligible freezing in the new context, irrespective of genotype and treatment (Figure 4A).

We also evaluated the ability of mice to discriminate the new location of an object in relation to spatial information using the OL test. Untreated Ts65Dn mice were incapable of discriminating the new location after a 24-hour retention interval. However, after lithium administration for 4 weeks, the Ts65Dn mice completely recovered spatial memory in the OL test (Figure 4B). The total object exploration time was not significantly different across genotype and treatment groups during the acquisition and trial phases, ruling out any interference due to animal motivation or amount of exploration (Supplemental Figure 6, A-C).

We also used the NOR test to evaluate the ability of mice to discriminate novelty in a complex setting of 3 different objects (49). Consistent with the results of previous studies (28), Ts65Dn mice were unable to discriminate the novel object over a 24-hour retention period. Notably, Ts65Dn mice treated with lithium for 4 weeks showed discrimination ability equivalent to WT littermates, indi- 
A

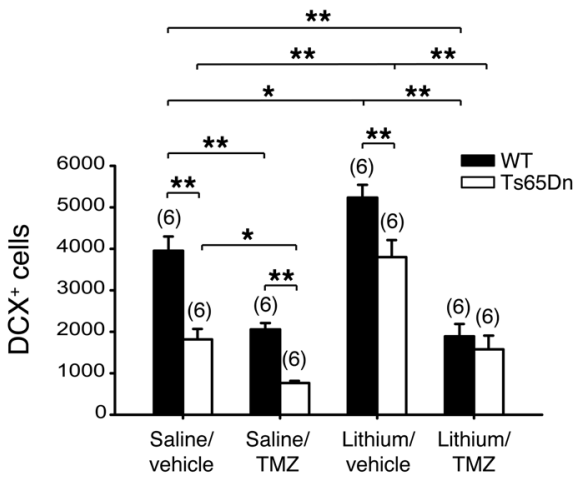

C

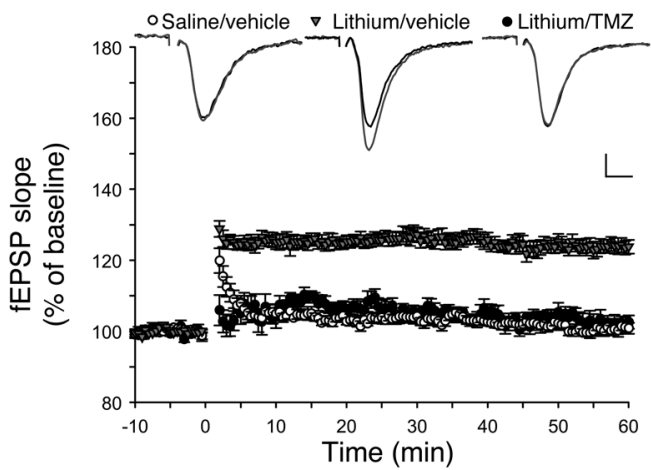

B

WT

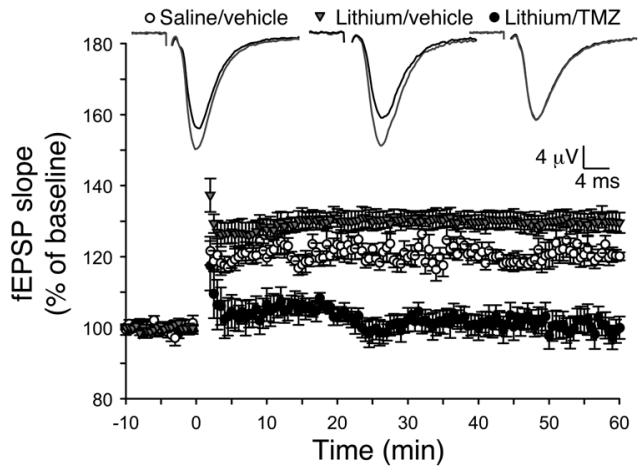

D

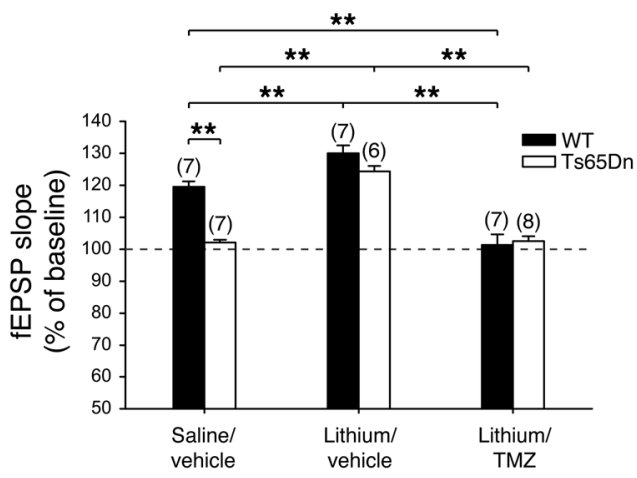

Figure 3

Adult neurogenesis was required for lithium-induced rescue of LTP in Ts65Dn mice. (A) Number of DCX+ newborn neurons in the DG of Ts65Dn and WT mice in which neurogenesis was inhibited using TMZ. 2-way ANOVA: genotype $\left(F_{1,40}=40.057, P<0.001\right)$, treatment $\left(F_{3,40}=47.089\right.$, $P<0.001)$, genotype $\times$ treatment $\left(F_{3,40}=3.375, P=0.028\right)$. (B) The inhibition of neurogenesis using TMZ prevented ACSF-LTP induction in slices obtained from lithium-treated WT mice $(P=0.690 \mathrm{vs}$. baseline). The LTP was normally induced in WT mice treated with either saline/vehicle $(P<0.001)$ or lithium/vehicle $(P<0.001)$. (C) The inhibition of neurogenesis using TMZ prevented ACSF-LTP induction in slices obtained from lithium-treated Ts65Dn $(P=0.105)$ mice. LTP was absent in Ts65Dn mice receiving saline/vehicle $(P=0.101)$ and was restored in the lithium-treated group $(P<0.001)$. The insets in panels $\mathbf{B}$ and $\mathbf{C}$ show representative fEPSP traces recorded 5 minutes before (black) and 45 minutes after (gray) LTP induction. (D) Quantification of the extent of ACSF-LTP elicited in the DG of WT and Ts65Dn mice. The numbers in parentheses indicate the number of brain slices recorded for each experimental group. 2-way ANOVA: genotype $\left(F_{1,36}=16.406, P<0.001\right)$, treatment $\left(F_{2,36}=70.531\right.$, $P<0.001)$, genotype $\times$ treatment $\left(F_{2,36}=11.404, P<0.001\right)$. ${ }^{\star} P<0.05 ;{ }^{* \star} P<0.01$ Tukey's post hoc test.

cating a full recovery of memory functions (Supplemental Figure 7, $\mathrm{A}$ and $\mathrm{B})$. The total exploration time during sessions and preference toward different objects in Ts65Dn mice following 4-week lithium treatment was similar to untreated Ts65Dn and WT mice (Supplemental Figure 7, C-E).

Next, we examined whether the effects of lithium on hippocampal-dependent cognitive tasks were dependent on functional neurogenesis. Consistent with the notion that newborn neurons younger than 1 week are not yet functionally integrated and the lack of LTP recovery in Ts65Dn mice after 1 week of lithium administration (Figure 2, E and F), we did not detect any improvement of memory deficits in the CFC (percentage freezing time, WT: $50.3 \pm 10.8, n=4$; Ts65Dn: $24.50 \pm 5.0, n=6 ; P<0.05$, Student's $t$ test), OL (discrimination index, WT: $25.2 \pm 5.2, n=11$; Ts65Dn: $1.1, \pm 7.8, n=11 ; P<0.05$, Student $t$ test), and NOR tests (Supplemental Figure 7B) after short-term lithium treatment.

We further investigated whether newborn neurons were required for the lithium-mediated rescue of hippocampus-dependent cognitive impairment through the administration of TMZ. Consistent with the observations in $\mathrm{DCX}^{+}$newborn neurons and neurogenesis-dependent ACSF-LTP (Figure 3), the lithium-induced cognitive recovery was abolished in Ts65Dn mice in which neurogenesis was concomitantly inhibited through TMZ administration. WT and Ts65Dn mice treated with both lithium and TMZ showed impaired contextual learning in the CFC test (Figure 4A) and were incapable of discriminating the new OL compared with mice treated with lithium alone (Figure 4B), indicating that newborn neurons are required to rescue hippocampal-mediated memory in Ts65Dn mice.

To assess the specificity of lithium for neurogenesis-dependent cognitive tasks, we examined working memory using the spontaneous alternation task. Working memory depends on intact hippocampal functions, engages several other brain areas (50), and appears to be independent of adult neurogenesis (51). Consistent with the results of previous studies (28), Ts65Dn mice could not alternate in the T-maze and performed close to chance level (Figure 4C). Notably, lithium treatment did not rescue Ts65Dn working memory performance in the T-maze. Total arm entries were similar across all genotype and treatment groups (Figure 4C). These results indicate that lithium specifically rescued Ts65Dn cognitive performance in cognitive memory domains sensitive to functional adult neurogenesis, without affecting other brain functions. 
A
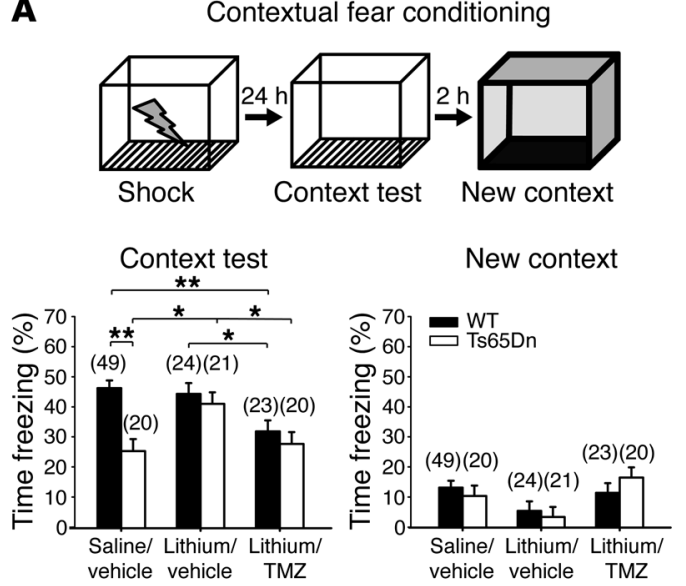

B

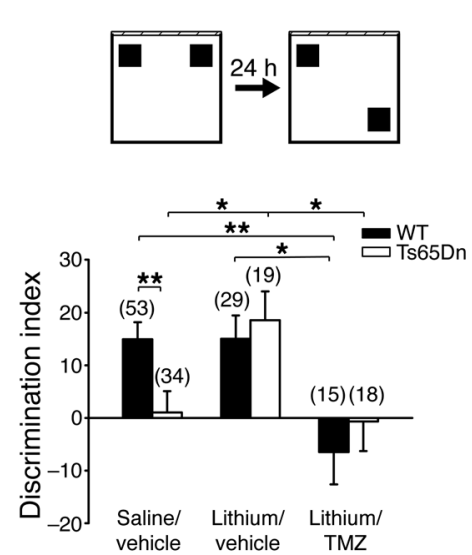

C
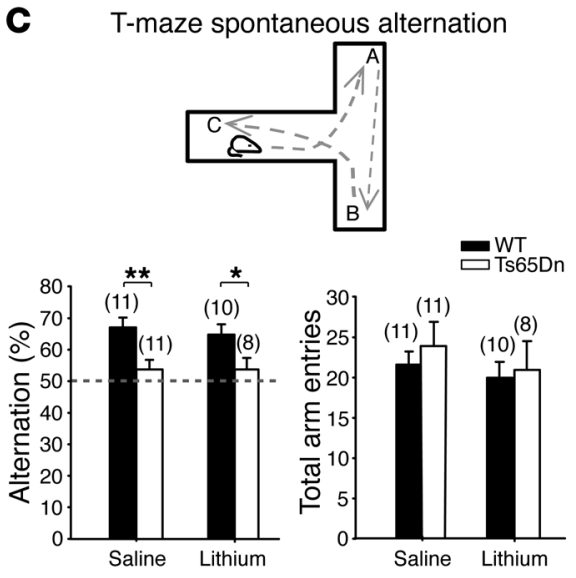

Figure 4

Reinstating adult neurogenesis rescued behavioral performance of Ts65Dn mice in CFC and OL tasks. (A) Ts65Dn contextual memory was rescued through a 4-week treatment with lithium. No effects were detected when mice were treated with lithium for 1 week. 2-way ANOVA: genotype $\left(F_{1,69}=10.107, P=0.002\right)$, treatment $\left(F_{2,69}=2.383, P=0.100\right)$, genotype $\times$ treatment $\left(F_{2,69}=2.589, P=0.082\right)$. No effect was observed when mice were exposed to a new context. 2-way ANOVA: genotype $\left(F_{1,69}=1.738, P=0.192\right)$, treatment $\left(F_{2,69}=0.551, P=0.579\right)$, genotype $\times$ treatment $\left(F_{2,69}=0.069, P=0.933\right)$. (B) Four weeks of lithium treatment fully rescued spatial memory deficits in Ts65Dn mice in the OL test. The inhibition of adult neurogenesis through TMZ prevented lithium effects. 2-way ANOVA: genotype $\left(F_{1,162}=0.123, P=0.726\right)$, treatment $\left(F_{2,162}=7.009\right.$, $P=0.001)$, genotype $\times$ treatment $\left(F_{2,162}=2.926, P=0.056\right)$. (C) Alternation in the T-maze test was reduced in Ts65Dn mice (dashed line indicates chance alternation) and was not affected by lithium. 2-way ANOVA: genotype $\left(F_{1,36}=13.816, P<0.001\right)$, treatment $\left(F_{1,36}=0.118, P=0.734\right)$, genotype $\times$ treatment $\left(F_{1,36}=0.127, P=0.724\right)$. The total number of arm entries during the test was not different across genotype and treatment. 2-way ANOVA: genotype $\left(F_{1,36}=0.345, P=0.560\right)$, treatment $\left(F_{1,36}=0.701, P=0.408\right)$, genotype $\times$ treatment $\left(F_{1,36}=0.051, P=0.823\right)$. In all panels, the numbers in parentheses indicate numbers of animals per group. ${ }^{\star} P<0.05$; ${ }^{\star \star} P<0.01$ Tukey's post hoc test.

Lithium restores neurogenesis in Ts65Dn mice through NPC proliferation. We determined whether lithium promoted adult neurogenesis through NPC proliferation or the survival of newly generated cells in Ts65Dn mice. The number of proliferating cells (as assessed using Ki67 staining) was decreased by 56\% in Ts65Dn mice (Figure 5, A and B). Amplifying precursors (type II cells) $(40,52)$ were also reduced by $41 \%$ in Ts65Dn mice, while the number of radial glia-like (RGL) progenitors (type I cells) was not significantly different from that in WT littermates (Figure 5, C-E). Lithium treatment for 4 weeks increased the number of amplifying progenitors and $\mathrm{Ki} 67^{+}$cells, thereby restoring the proliferation of NPCs in Ts65Dn mice (Figure 5, B and E).

BrdU birth dating (Figure 6A) confirmed the impairment of NPC proliferation in the DG of Ts65Dn mice, showing that $\mathrm{BrdU}^{+}$cells were reduced by $48 \%$ compared with those in WT mice (Figure 6 , $\mathrm{B}$ and $\mathrm{C}$ ). This impairment was paralleled by a $57 \%$ reduction in the number of $\mathrm{BrdU}^{+}$newly generated neurons expressing the mature neuronal marker NeuN in the DG of trisomic mice (Figure 6, $\mathrm{D}$ and $\mathrm{E})$. Notably, lithium promoted the proliferation of NPCs in the DG of Ts65Dn mice (Figure 6C) and restored the number of newly generated $\mathrm{BrdU}^{+} \mathrm{NeuN}^{+}$neurons at 4 weeks after $\mathrm{BrdU}$ administration (Figure 6E).

In addition, we examined the survival of newly generated cells and their commitment toward the neuronal lineage in lithiumtreated and untreated mice. The total numbers of surviving $\mathrm{BrdU}^{+}$cells and their progeny at 4 weeks after BrdU administration were reduced by $54 \%$ in untreated Ts 65 Dn mice. However, the survival rate of $\mathrm{BrdU}^{+}$cells in all Ts65Dn treatment groups was similar to that in the untreated WT littermates (Figure $6 \mathrm{G}$ ). This indicates that the reduction of newborn neurons in Ts65Dn mice was not a consequence of cell death and that lithium did not affect the survival of newly generated cells. Consistently, the number of apoptotic cells was not significantly different between untreated or lithium-fed Ts65Dn mice and WT untreated littermates (Supplemental Figure 8). In WT mice, despite enhanced NPC proliferation (59\% over basal), lithium treatment did not enhance the total number of surviving $\mathrm{BrdU}^{+}$ cells or newly generated neurons $\left(\mathrm{BrdU}^{+} \mathrm{NeuN}{ }^{+}\right)$, resulting in a significant reduction in the survival rates of these cells. This suggests the existence of physiological regulatory mechanisms that balance the excess production of newly generated cells in WT mice as previously proposed (53). This view is supported by the observation that the number of apoptotic cells was significantly increased in the DG of WT mice after lithium treatment (Supplemental Figure 8), and the number of $\mathrm{BrdU}^{+} \mathrm{NeuN}^{+}$ newborn neurons was similar in both lithium-treated WT and Ts65Dn mice (Figure 6E).

Finally, the phenotypic analysis of newly generated $\mathrm{BrdU}^{+}$cells revealed that the percentage of $\mathrm{BrdU}^{+} \mathrm{GFAP}^{+}$cells was similar in treated and untreated WT and Ts65Dn mice. Conversely, a slightly significant reduction (5\%) of the percentage of $\mathrm{BrdU}^{+} \mathrm{NeuN}^{+}$over the total number of $\mathrm{BrdU}^{+}$cells was observed in untreated Ts65Dn mice. Lithium treatment restored the $\mathrm{BrdU}^{+} \mathrm{NeuN}^{+}$cell number, suggesting that the altered acquisition of the neuronal phenotype might also partially contribute to the impaired generation of newborn neurons in trisomic mice (Figure $6 \mathrm{H}$ ).

The Wnt/ $\mathrm{W}$-catenin pathway is required to promote NPC proliferation. The Wnt/ $\beta$-catenin signaling pathway plays a key role in regulating DG adult neurogenesis (39) and is involved in regulating hippocampal NPC proliferation upon lithium stimulation in vitro (38). To confirm the activation of this pathway upon lithium administration (54), we evaluated the amount of active $\beta$-catenin 


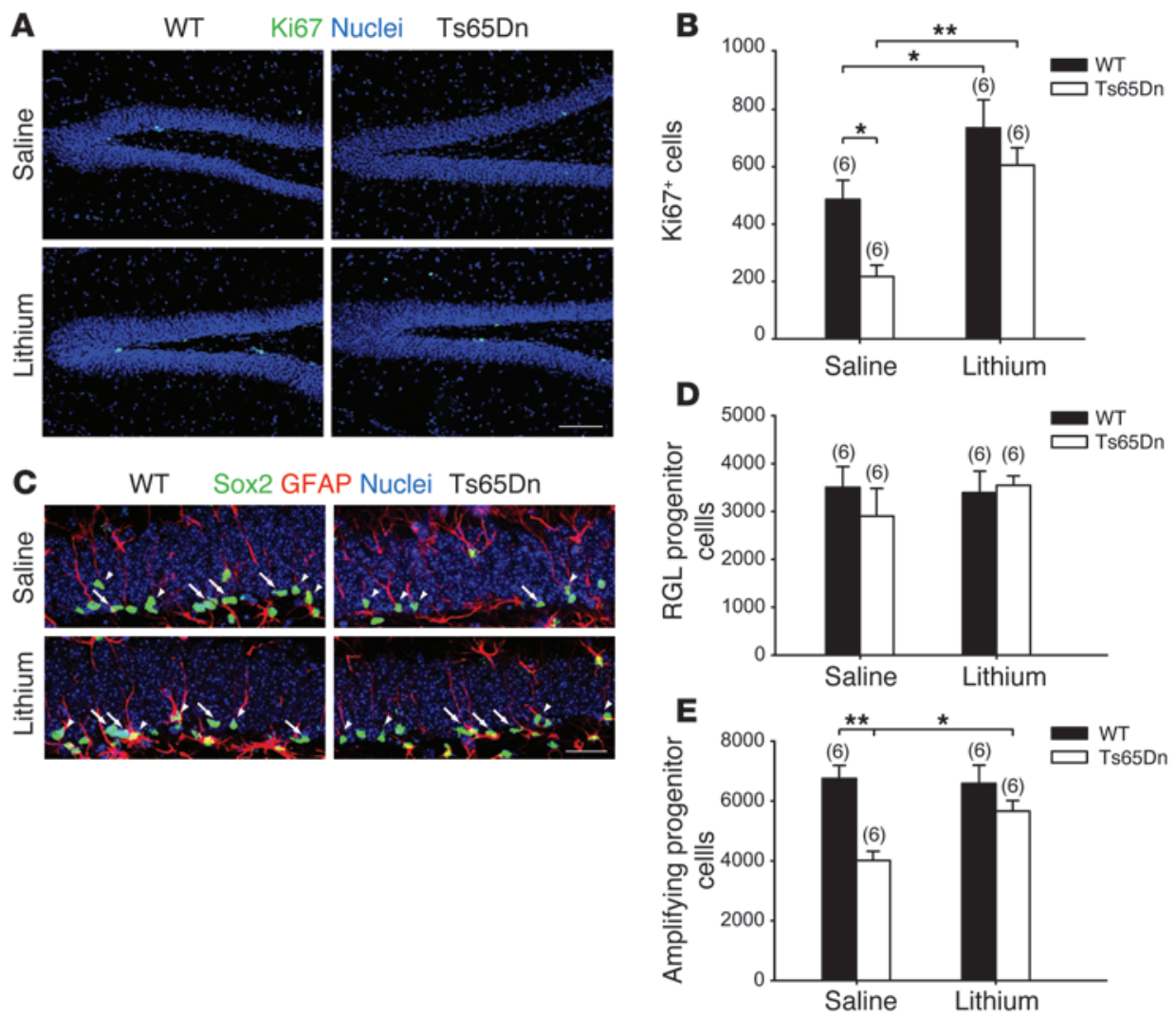

\section{Figure 5}

Lithium restored the number of proliferating cells and increased the number of amplifying progenitors in Ts65Dn mice. (A) Ki67 immunoreactivity (green) and nuclei counterstaining with Hoechst-33342 (blue). Scale bar:100 $\mu \mathrm{m}$. (B) Number of Ki67-stained cells. Proliferating cells were reduced in saline-treated Ts65Dn mice. Lithium treatment for 4 weeks significantly increased the number of Ki67+ cells in WT mice (black bars) and restored their number to physiological levels in Ts65Dn mice (white bars). 2-way ANOVA: genotype $\left(F_{1,20}=8.383, P=0.009\right)$, treatment $\left(F_{1,20}=21.493, P<0.001\right)$, genotype $\times$ treatment $\left(F_{1,20}=1.029, P=0.322\right)$. (C) RGL progenitors (arrowheads) and amplifying progenitors (arrows) immunoreactive for GFAP (red) and Sox2 (green) and counterstained with Hoechst-33342 (blue). Scale bar: $25 \mu \mathrm{m}$. (D and E) Number of RGL progenitors and amplifying progenitors was evaluated by counting GFAP- and Sox2-positive cells with or without radial morphology (see Methods). (D) Number of RGL progenitors in lithium- or saline-treated mice showed no differences across groups. 2-way ANOVA: genotype $\left(F_{1,20}=0.261, P=0.615\right)$, treatment $\left(F_{1,20}=0.364, P=0.553\right)$, genotype $\times$ treatment $\left(F_{1,20}=0.746\right.$, $P=0.398$ ). (E) Number of amplifying progenitors was reduced in Ts65Dn mice and significantly increased by lithium treatment. 2-way ANOVA: genotype $\left(F_{1,20}=17.155, P<0.001\right)$, treatment $\left(F_{1,20}=2.772\right.$, $P=0.112)$, genotype $\times$ treatment $\left(F_{1,20}=4.217, P=0.053\right) .{ }^{*} P<0.05 ;{ }^{\star \star} P<0.01$, Tukey's post hoc test. Numbers in parentheses indicate the number of animals analyzed in each group.

(i.e., dephosphorylated at Ser37 and Thr41) $(55,56)$ in hippocampal lysates from WT and Ts65Dn mice using quantitative multiplex fluorescent Western blotting (57). Lithium treatment effectively increased the ratio of active $\beta$-catenin to total $\beta$-catenin in both WT and Ts65Dn hippocampi. Notably, the extent of lithium-induced $\beta$-catenin activation was significantly greater in Ts65Dn mice (48\%) than in their WT littermates (18\%) (Figure 7A).

To investigate whether the lithium-mediated stimulation of this pathway induces NPC proliferation in Ts65Dn mice in a cell-autonomous manner, we established in vitro cultures of adult dentate NPCs (ADNPCs) (58) from WT and Ts65Dn mice. We first examined whether the proliferation of ADNPCs from Ts65Dn mice was altered in vitro. Proliferating ADNPCs from WT and Ts65Dn mice expressed comparable levels of the pre- cursor markers Nestin and Sox2 (Figure 7B). BrdU incorporation experiments demonstrated that the proliferation of Ts65Dn ADNPCs was significantly reduced compared with WT cultures (Figure 7, $\mathrm{C}$ and D). Consistent with in vivo findings, lithium treatment almost doubled ADNPC proliferation in both WT and Ts65Dn cultures. Notably, the percentage of $\mathrm{BrdU}^{+}$ cells in Ts65Dn cultures was restored to levels indistinguishable from untreated WT ADNPCs.

The activation of the Wnt pathway leads to the stabilization and nuclear translocation of $\beta$-catenin, which, in turn, activates the expression of Wnt target genes through interactions with members of the $\mathrm{T}$ cell factor/lymphoid enhancer factor (TCF/LEF) family of transcription factors (59). We therefore verified whether the canonical Wnt/ $\beta$-catenin pathway was activated through lithium treatment in ADNPCs using the TOPFlash and FOPFlash luciferase reporter assay (60). Treatment with recombinant Wnt3a significantly increased $\beta$-catenin/ TCF-dependent transcription in both WT (fold induction \pm SEM: $11.67 \pm 2.02 ; P<0.01$ versus basal, unpaired $t$ test) and Ts65Dn ADNPCs (fold induction \pm SEM: $9.81 \pm 1.97 ; P<0.01$ versus basal, unpaired $t$ test) and achieved similar levels of activity in both WT and Ts65Dn cells (NS, unpaired $t$ test), indicating that this pathway is functional upon ligand stimulation. Notably, lithium significantly enhanced $\beta$-catenin/TCF-dependent transcription in ADNPCs from WT and Ts65Dn mice under basal conditions and in the presence of Wnt3a (Figure 7E), confirming that lithium induces the activation of $\mathrm{Wnt} / \beta$-catenin signaling.

Moreover, we assessed whether the Wnt/ $\beta$-catenin/TCF pathway was required for the proliferative effects of lithium. To inhibit the $\beta$-catenin function, we transfected ADNPCs from WT and Ts65Dn mice with a dominant negative form of TCF4 (dnTCF) (61) together with the fluorescent reporter protein mCherry (dnTCF-mCherry). Lithium-induced proliferation was completely abolished in ADNPCs transfected with dnTCF-mCherry, while the expression of mCherry alone neither affected basal nor lithium-induced proliferation in both WT and Ts65Dn ADNPCs (Figure 7F). The baseline activity of Wnt signaling in cultured ADNPCs was modest, and the expression of dnTCF did not substantially affect the basal proliferation rate of ADNPCs (Figure 7F), consistent with previous reports 
A

\begin{tabular}{lllll} 
A & \multicolumn{5}{c}{ Lithium or normal diet } \\
Week of \\
treatment
\end{tabular}
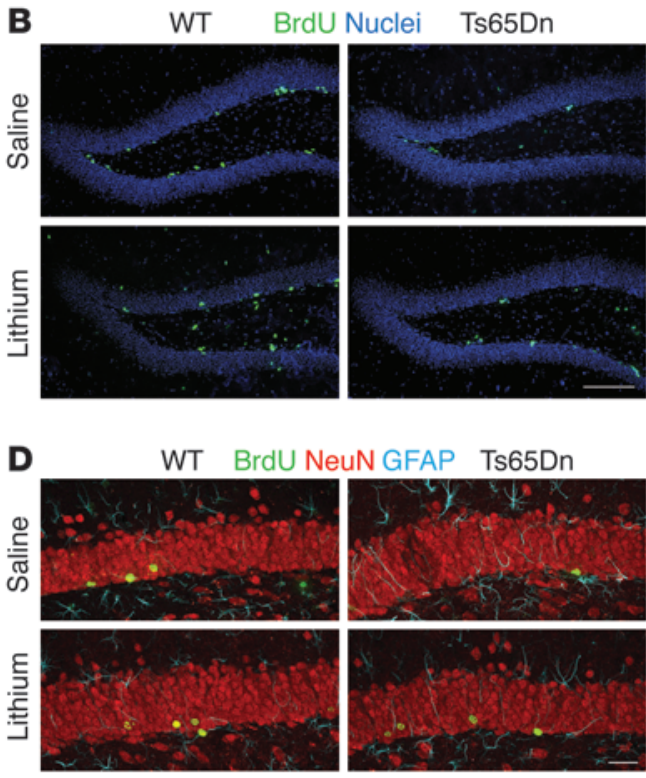

$\mathbf{F}$

Survival

(4 weeks after BrdU)

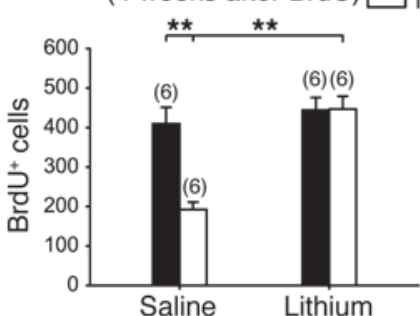

C

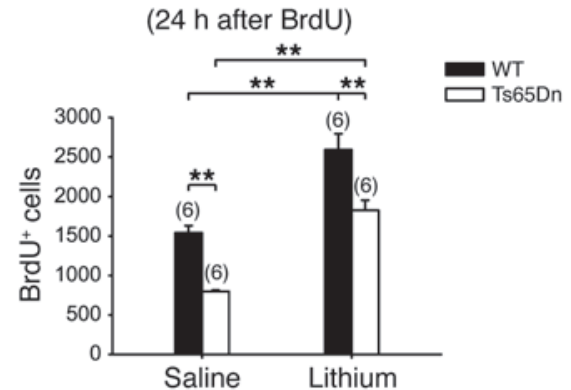

E New neurons

(4 weeks after BrdU)

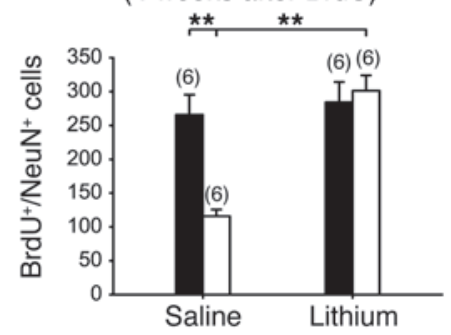

Survival

(BrdU + at 4 wks/

$\mathrm{BrdU}^{+}$at $24 \mathrm{~h}$ )
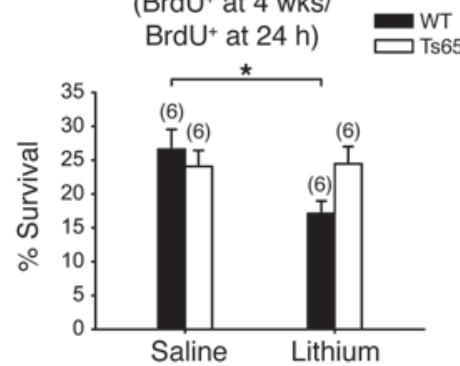

Phenotype

(\% of $\mathrm{BrdU}^{+}$cells at 4 wks)

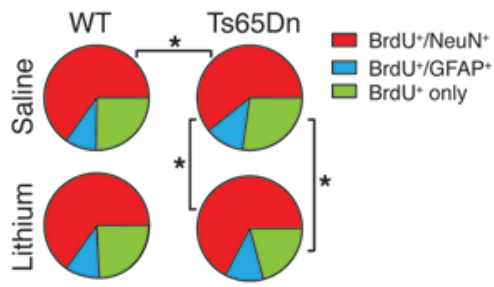

Figure 6

Lithium restored neurogenesis by promoting NPC proliferation in DG of Ts65Dn mice. (A) Experimental design. (B) BrdU immunoreactivity (green) and nuclei counterstaining with Hoechst-33342 (blue). Scale bar: $100 \mu \mathrm{m}$. (C) Number of BrdU+ cells in mice sacrificed at 24 hours after BrdU administration. 2-way ANOVA: genotype $\left(F_{1,20}=34.753, P<0.001\right)$, treatment $\left(F_{1,20}=65.834, P<0.001\right)$, genotype $\times$ treatment $\left(F_{1,20}=0.009, P=0.921\right)$. (D) BrdU (green), NeuN (red), and GFAP (cyan) immunoreactivity of brain slices from mice sacrificed at 4 weeks after BrdU administration. Scale bar: $25 \mu \mathrm{m}$. (E and $\mathbf{F})$ Number of newly generated neurons $\left(\mathrm{BrdU}^{+} \mathrm{NeuN}^{+}\right)\left(\mathbf{E} ; 2\right.$-way ANOVA: genotype $\left[F_{1,20}=5.311\right.$,

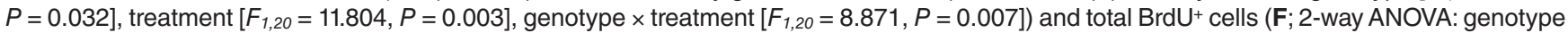
$\left[F_{1,20}=7.430, P=0.013\right]$, treatment $\left[F_{1,20}=19.013, P<0.001\right]$, genotype $\times$ treatment $\left.\left[F_{1,20}=12.480, P=0.002\right]\right)$ in DG of Ts65Dn and WT mice 4 weeks after BrdU administration. (G) Survival rate of $\mathrm{BrdU}^{+}$cells and their progeny. 2-way ANOVA: genotype $\left(F_{1,20}=1.293, P=0.2690\right)$, treatment $\left(F_{1,20}=2.335, P=0.1422\right)$, genotype $\times$ treatment $\left(F_{1,20}=5.410, P=0.0307\right)$. $(\mathbf{H})$ Percentage distribution of $\mathrm{BrdU}^{+} \mathrm{NeuN}^{+}, \mathrm{BrdU}^{+} \mathrm{GFAP} \mathrm{P}^{+}$, and $\mathrm{BrdU}^{+}$only-labeled cells. 2-way ANOVA for BrdU+NeuN+: genotype $\left(F_{1,20}=0.381, P=0.544\right)$, treatment $\left(F_{1,20}=0.974, P=0.336\right)$, genotype $\times$ treatment $\left(F_{1,20}=5.758, P=0.0264\right)$. 2-way ANOVA for BrdU+GFAP+: genotype $\left(F_{1,20}=1.958, P=0.177\right)$, treatment $\left(F_{1,20}=0.162, P=0.691\right)$, genotype $\times$ treatment $\left(F_{1,20}=0.643, P=0.432\right)$. 2-way ANOVA for BrdU+ only: genotype $\left(F_{1,20}=0.105, P=0.749\right)$, treatment $\left(F_{1,20}=0.388\right.$, $P=0.540)$, genotype $\times$ treatment $\left(F_{1,20}=6.884, P=0.016\right) .{ }^{\star} P<0.05$; ${ }^{\star \star} P<0.01$, Tukey's $(\mathbf{C}$ and $\mathbf{E}-\mathbf{G})$ or Bonferroni's $(\mathbf{H})$ post hoc tests. Numbers in parentheses indicate the number of animals analyzed in each group.

showing that the knockdown of $\beta$-catenin did not affect the basal proliferation of adult hippocampal progenitors in culture (38).

Overall, these data indicate that lithium activates the Wnt/ $\beta$-catenin pathway in the hippocampus in vivo and that this pathway is required for the effects of lithium on ADNPC proliferation.

\section{Discussion}

Our findings demonstrate that promoting adult neurogenesis mediates the functional recovery of synaptic plasticity in the DG and rescues behavioral performance in hippocampal-mediated tasks in a relevant mouse model of DS. Lithium, a well-established 
A Active
$\beta$-Catenin
Total
$\beta$-Catenin
Merge
WT/saline Ts65Dn/saline WT/lithium Ts65Dn/lithium
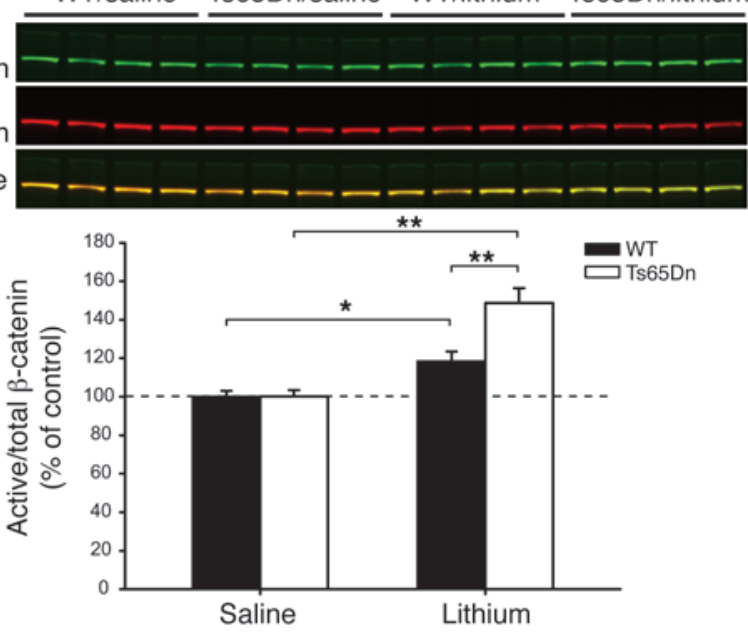

C

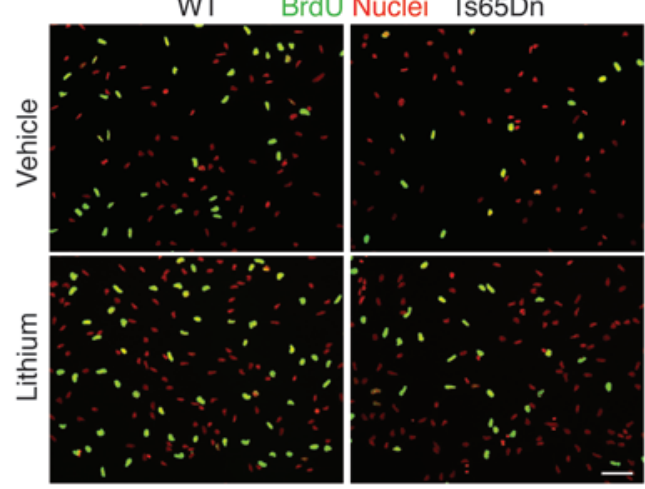

$\mathbf{E}$

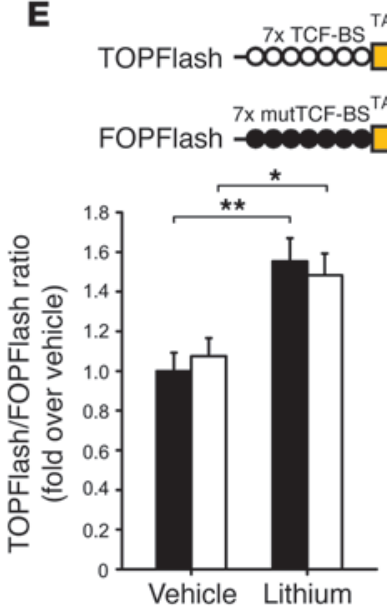

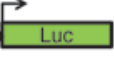

$\stackrel{T A}{\longrightarrow} \rightarrow$

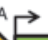

\section{(1)

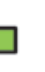
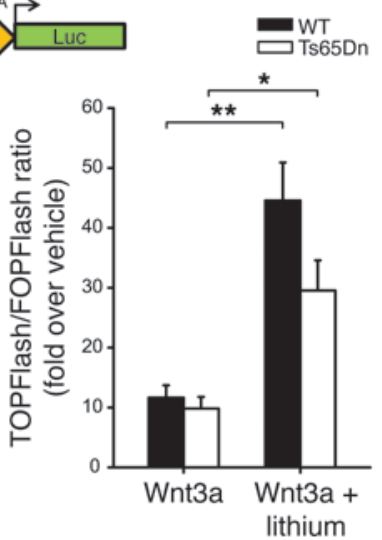

B
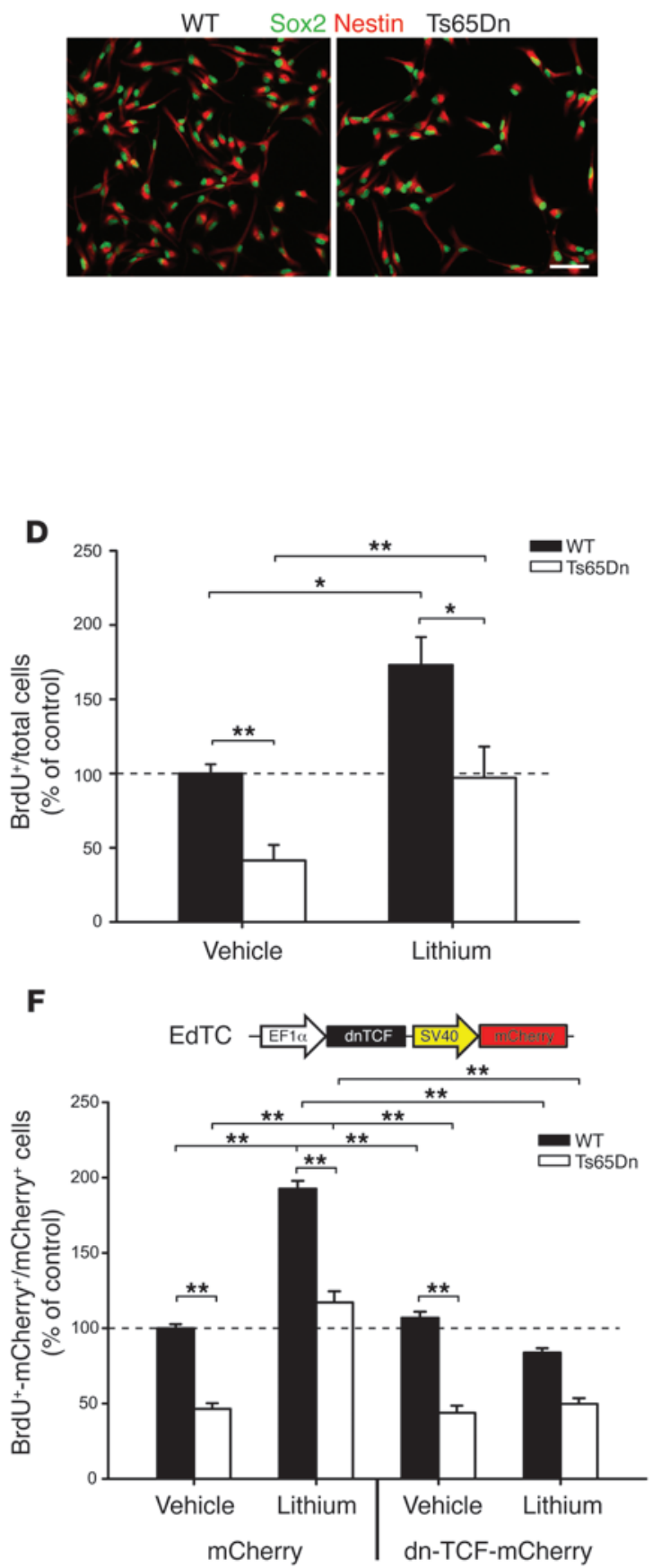

Figure 7

Lithium rescued proliferation of Ts65Dn NPCs through stimulation of $\beta$-catenin pathway. (A) Multiplex fluorescence Western blot analysis of active form of $\beta$-catenin in hippocampal lysates from WT and Ts65Dn mice. The ratio of active $\beta$-catenin (green) to total $\beta$-catenin (red). 2 -way ANOVA: genotype $\left(F_{1,12}=8.576, P=0.013\right)$, treatment $\left(F_{1,12}=41.168, P<0.001\right)$, genotype $\times$ treatment $\left(F_{1,12}=8.439, P=0.013\right)$. (B) ADNPC immunoreactivity for the progenitor markers Sox2 (green) and Nestin (red). (C) BrdU immunoreactivity (green) in ADNPCs counterstained with DAPI (red). Scale bars: $20 \mu \mathrm{m}$. (D) Percentage of BrdU+ cells in Ts65Dn ADNPCs treated with lithium (2 mM LiCl) or vehicle. 2-way ANOVA: genotype $\left(F_{1,12}=17.431, P<0.001\right)$, treatment $\left(F_{1,12}=19.044, P<0.001\right)$, genotype $\times$ treatment $\left(F_{1,12}=0.317, P=0.584\right),(n=4) .(\mathrm{E}) \mathrm{Wnt} / \beta-\mathrm{catenin}$ pathway activation as detected using the TOPFlash and FOPFlash plasmid luciferase reporter assay. Treatment with lithium increased luciferase activity in ADNPCs under basal conditions (1-way ANOVA $\left[F_{3,20}=7.448, P=0.002\right]$ ) and upon stimulation with $10 \mathrm{ng} / \mathrm{ml}$ of Wnt3a (1-way ANOVA $\left.\left[F_{3,20}=14.643, P<0.001\right]\right)$. $(F)$ Proliferation analysis in ADNPCs transfected with dnTCF-mCherry (EdTC) or control mCherry plasmids. Proliferation was expressed as the ratio of $\mathrm{BrdU}^{+} \mathrm{mCherry}^{+}$double-labeled cells to total mCherry ${ }^{+}$cells $(n=4)$. 2-way ANOVA: genotype $\left(F_{1,24}=357.0\right.$, $P<0.001)$, treatment $\left(F_{3,24}=194.0, P<0.001\right)$, genotype $\times$ treatment $\left(F_{3,24}=8.446, P<0.001\right) .{ }^{*} P<0.05$; ${ }^{* \star} P<0.01$, Tukey's post hoc test. 
mood stabilizer, stimulates NPC proliferation and increases the number of maturing DG newborn neurons in trisomic mice. These neurons are functionally active, as demonstrated by the complete recovery of newborn neuron-dependent LTP in the DG of lithium-treated Ts65Dn mice, and are required to restore learning and memory performance in trisomic mice. The neurogenesis-promoting effects of lithium are associated with the activation of the Wnt/ $\beta$-catenin pathway in vivo, and functional signaling through this pathway is required for the lithium-induced proliferation of both trisomic and WT ADNPCs in vitro.

Consistent with previous results $(28,29)$, we observed that LTP elicited in the absence of $\mathrm{GABA}_{\mathrm{A}}$ receptor blockers (ACSF-LTP) is deficient in Ts65Dn mice. It has been demonstrated that this form of LTP is dependent on functional DG newborn neurons, which express glutamate receptors containing the NR2B subunit $(1,2,7)$. The lack of ACSF-LTP in trisomic mice is indeed consistent with the reduced number of newborn neurons in the DG (Figure 1). Notably, chronic lithium administration restores the proliferation of NPCs and the generation of newborn neurons, leading to the full recovery of Ro25-6981-sensitive LTP in trisomic mice. Moreover, LTP was not induced when trisomic and WT mice were administered lithium in combination with the cytostatic drug $\mathrm{TMZ}$, indicating that neurogenesis is required for LTP induction when the GABAergic system is not inhibited. Thus, short-term treatment (e.g., 1 week) with lithium did not restore hippocampal synaptic plasticity in Ts65Dn mice, thereby ruling out the involvement of other acute effects of lithium and further supporting the notion that functional neurogenesis is specifically involved in reverting the hippocampal-dependent disease phenotype. Indeed, newborn neurons 1-week old or younger do not show any spontaneous or evoked synaptic currents and are not integrated in the hippocampal circuits $(4,62)$. Indeed, the enhanced synaptic plasticity properties of these cells are expressed at 3-4 weeks after their birth and last until 6 weeks $(2,3)$.

The recovery of neurogenesis and newborn neuron-dependent LTP in Ts65Dn mice specifically rescues behavioral performance in 3 distinct hippocampal-dependent tasks (i.e., CFC, OL, and NOR) but does not rescue working memory (i.e., T-maze alternation). This finding is consistent with previous studies showing that contextual learning $(7,9,10)$, spatial memory, and object discrimination $(44,45,47,63)$ rely on hippocampal adult neurogenesis, while working memory engages several brain areas, including the prefrontal cortex, basal forebrain, hippocampus, and striatum (50), and is independent of adult neurogenesis (51). Chronic treatment with lithium also increased the number of newborn neurons and neurogenesis-dependent LTP in WT mice. However, these effects do not translate into behavioral benefits. This finding is consistent with recent data demonstrating that increasing the number of $\mathrm{DCX}^{+}$newborn neurons through the genetic inhibition of apoptosis potentiates neurogenesis-dependent LTP in the DG without affecting the performance of WT mice in CFC or NOR tests (12). The lack of behavioral benefits in WT mice upon neurogenesis induction could reflect the existence of physiological regulatory mechanisms balancing the excess production of newly generated cells in WT mice (53). This concept is supported by evidence that the number of $\mathrm{NeuN}^{+}$newborn neurons is not increased upon the enhancement of neurogenesis (12). Consistently, in WT mice, lithium neither enhanced the total number of surviving $\mathrm{BrdU}^{+}$cells nor newly generated $\mathrm{BrdU}^{+} \mathrm{NeuN}^{+}$neurons, resulting in a significant reduction of their survival rates. Accordingly, apoptotic cells were significantly increased after the administration of lithium in the DG of WT mice (Supplemental Figure 8), and the number of $\mathrm{BrdU}^{+} \mathrm{NeuN}^{+}$newborn neurons was similar in both lithium-treated WT and Ts65Dn mice (Figure 6E), supporting the notion that lithium cannot stimulate adult neurogenesis over physiological levels.

Although we acknowledge that lithium might exert diverse pleiotropic effects, such as the modulation of brain myo-inositol levels (64), our data consistently support the idea that the amelioration of adult neurogenesis underlies lithium effects on behavioral performance in Ts65Dn mice, as revealed by the inability of lithium to restore cognitive performance when administered for 1 week or in combination with the cytostatic drug TMZ. Notably, the functional effects (i.e., LTP loss) of neurogenesis knockdown appear only when the number of newborn neurons is reduced beyond a critical threshold. Indeed, the effects of TMZ on $\mathrm{DCX}^{+}$ neuron number are dose dependent. However, only a $25 \mathrm{mg} / \mathrm{kg}$ dose of TMZ abolishes the LTP of newborn neurons in WT mice. This finding is reminiscent of findings in neurodegenerative disorders where clinical symptoms are observed after pathological lesions have produced a significant level of damage $(65,66)$.

The etiology of DS intellectual disability remains poorly understood. Consistent data suggest that Ts65Dn cognitive impairment might arise from an imbalance of excitatory and inhibitory neurotransmission $(28,29,67)$. It has been shown that the GABA antagonists PTX and bilobalide rescue the behavioral deficits of Ts65Dn mice when administered for at least 2 consecutive weeks (28). Emerging evidence indicates that GABA can also affect hippocampal function through neurogenesis $(62,68)$. Indeed, GABAergic inputs to hippocampal progenitor cells reduce NPC proliferation, promote activity-dependent neuronal differentiation (68), and regulate the synaptic integration of newly generated neurons in the adult hippocampus (62). Within this context, we cannot exclude the idea that an imbalance in the excitatory/inhibitory neurotransmission could at least partially contribute to the overall impairment of adult neurogenesis in the context of DS. However, our data on cultured ADNPCs clearly indicate that cellautonomous mechanisms are involved in determining the defective proliferation of Ts65Dn precursors, suggesting that intrinsic neurogenetic pathways might be altered in DS.

The Wnt/ $\beta$-catenin canonical pathway is a key regulator of NPC proliferation and neuronal fate commitment (39) and is activated by lithium (38). Consistently, we observed that lithium administration activates this pathway in the hippocampus of WT and Ts65Dn mice. It has been shown that adult hippocampal NPCs express receptors and signaling components for Wnt proteins, and the Wnt/ $\beta$-catenin pathway is active in the neurogenic niche of adult WT mice (39). Notably, the overexpression of Wnt 3 enhances neurogenesis, which is almost completely abolished by the inhibition of Wnt signaling in vitro and in vivo (39). Here, we show that the reduced proliferation of Ts65Dn ADNPCs is fully restored after lithium treatment. This recovery is inhibited upon the expression of a dominant negative form of TCF4, which is a fundamental effector that acts downstream of $\beta$-catenin (59). Although this indicates that Wnt signaling is essential for the lithium-induced proliferation of trisomic NPCs, based on the present findings, we cannot rule out that other neurogenic pathways might also underlie adult neurogenesis impairment in DS. For example, the agonist Sonic Hedgehog (Shh) increases the number of cerebellum granule precursor cells when injected into Ts65Dn neonates (33). Shh signaling also appears to be active in adult DG stem cells (69). 
However, the role of this pathway in DS adult neurogenesis remains unclear. Moreover, the Notch signaling pathway, which is downregulated by DS-associated kinase DIRK1A (70), is also crucial for maintaining an essential population of NPCs for DG adult neurogenesis (71) and determining cell fate and newborn neuron differentiation (72). Further studies are warranted to identify abnormal neurogenetic pathways in DS and/or their potential exploitation for therapies.

In conclusion, our findings strongly indicate that lithium-induced adult neurogenesis might have a profound impact on hippocampal synaptic plasticity and memory in the Ts65Dn mouse model of DS. Studies in DS patients $(25,73,74)$ suggest that hippocampal dysfunction affects cognitive functions that are typically regulated through adult neurogenesis, such as pattern separation (13) and cognitive flexibility (11), thus providing a conceptual framework for clinical testing of lithium-based therapies in DS. Importantly, the effects of lithium manifest at doses achieving serum and brain concentrations (Supplemental Figure 2) consistent with the human therapeutic range $(0.5-1.2 \mathrm{mEq} / \mathrm{l})(75)$. Thus, our data propose that lithium-based therapies should be further explored in patients in the near future, considering the increased prevalence of DS in the European Union (76) and USA (77) over the past decades and the increased life expectancy of DS patients consequent to improved medical care $(78,79)$. Conversely, from a long-term perspective, our findings implicate adult neurogenesis as a potential target for future therapies to treat cognitive disabilities in DS patients.

\section{Methods}

\section{Animals and treatment}

Female Ts65Dn mice carrying a partial trisomy of chromosome 16 (34) were obtained from the Jackson Laboratories and maintained on the original genetic background by mating to C57BL/6JEi × C3SnHeSnJ (B6EiC3) F1 hybrid males. A veterinarian was employed to control animal health and comfort. The mice were housed in filtered cages in a temperature-controlled room with a 12-hour dark/12-hour light cycle and were provided access to water and food ad libitum. The animals were genotyped using multiplex ligation-dependent probe amplification (MLPA) with a set of 16 probes previously validated for Ts65Dn trisomic mice (80). WT littermates were used as controls throughout the study.

At 5 to 6 months of age, male Ts65Dn and WT littermates (4 to 6 animals/cage) were randomly assigned to the treatment or control groups. The animals in the treatment groups received either standard chow (Mucedola) or a diet containing $\mathrm{Li}_{2} \mathrm{CO}_{3}(2.4 \mathrm{~g} / \mathrm{kg}$ of chow) for 1 or 4 weeks as previously described (37). The serum and brain concentrations of lithium were assessed after 1 and 4 weeks of treatment using inductively coupled plasma mass spectrometry (ICP-MS). To reduce potential lithium toxicity in the kidney, a saline bottle was provided in addition to water to all cages (37). The animals in the untreated groups received standard food pellets and water and saline bottles.

For the TMZ treatment, doses (12.5 and $25 \mathrm{mg} / \mathrm{kg}$ of body weight) previously shown to inhibit DG neurogenesis without causing detectable side effects on weight, motor activity, or inflammation were used (11). TMZ or the corresponding vehicle (12.5\% DMSO in saline) was i.p. injected into mice every other day for 3 weeks, and the subsequent experiments were performed 1 week later.

For neuron birth dating, BrdU was administered at $50 \mathrm{mg} / \mathrm{kg}$ body weight through daily i.p. injections during the fourth week of lithium treatment. The mice were sacrificed at 24 hours or 4 weeks after the last BrdU injection (81).

\section{Behavioral testing}

Various cohorts of mice were used for behavioral testing. Each cohort comprised male Ts65Dn mice and WT littermates. The mice were tested after 1 week of lithium treatment (acquisition on day 6 and trial on day 7) or during the fourth week of lithium treatment. Hippocampal-mediated learning and memory was assessed using the OL test, the NOR test, and the CFC test. Working memory was tested using the T-maze spontaneous alternation test. For the OL and NOR tests, animal behavior was videotaped throughout all experimental sessions and subsequently analyzed by a trained operator blinded to the experimental groups. The motor activity was evaluated using a video tracking system (Any-Maze; Ugo Basile) for a period of 15 minutes in the same chamber used for the NOR test.

OL test. This test measures spatial memory through an evaluation of the ability of mice to recognize the new location of a familiar object with respect to spatial cues. Testing was conducted in a black acrylic chamber $(44 \times 44 \mathrm{~cm})$ with white strips on 1 wall of the chamber. The mice were first acclimated to the chamber for 15 minutes 1 day prior to testing. The mice were exposed to 2 identical objects for 15 minutes during the acquisition phase and tested at 24 hours later. Object preference was evaluated during this session. During the trial session, one of the objects was moved to a novel location, and the mice were allowed to explore the objects for 15 minutes. The objects were cleaned with $70 \%$ ethanol after each trial. The time spent exploring each object was measured. Exploration was considered as any investigative behavior (i.e., head orientation, sniffing occurring within $<1.0 \mathrm{~cm}$ ) or deliberate contact occurring with each object. A discrimination index was calculated as the percentage of time spent investigating the object in the new location minus the percentage of time spent investigating the object in the old location: discrimination index $=$ (new OL exploration time/total exploration time $\times 100$ ) - (old OL exploration time/total exploration time $\times 100$ ).

NOR test. The NOR test is based on the natural propensity of rodents to preferentially explore novel objects over familiar ones. The experimental procedure was performed as previously described in DS mouse models $(28,49)$. Testing was conducted in a black acrylic chamber $(44 \times 44 \mathrm{~cm})$ equipped with a digital video recording system. The objects used during the task were different in shape, color, size, and material (metal, glass, plastic). The mice were acclimated to the chamber for 15 minutes. The following day, the mice were placed in the same chamber with 3 different objects for a 15-minute acquisition sessions. Object preference was evaluated during these sessions. Twenty-four hours later, mice were subjected to a 15 -minute testing session, during which they were presented with 2 familiar and 1 novel object. The objects were counterbalanced between the sessions and were cleaned with $70 \%$ ethanol after each trial. The time spent exploring each object was measured, and the discrimination index was calculated as the difference between the percentages of time spent investigating the novel object and the time spent investigating the familiar objects: (discrimination index $=($ novel object exploration time $/$ total exploration time $\times 100)-$ (familiar object exploration time/total exploration time $\times 100$ ).

CFC test. The single-shock CFC test was performed as previously described (46). The mice were placed in a fear conditioning system (TSE) consisting of a transparent acrylic conditioning chamber $(23 \times 23 \mathrm{~cm})$ equipped with an array of infrared sensors to monitor the animal's movements and a stainless-steel grid floor. The chamber was cleaned with $70 \%$ ethanol after each trial. The mice were placed in the chamber and after 3 minutes, received an electric shock ( $2 \mathrm{~s}, 0.75 \mathrm{~mA}$ constant electric current) through the floor grid. The mice were removed at 15 seconds after the shock. Twenty-four hours later, the mice were placed in the same chamber for 3 minutes and, after 2 hours, were moved to a new context (black chamber with plastic gray floor and mint-flavored odor). The freezing behavior was automatically scored using the TSE multiconditioning system software. 
T-maze spontaneous alternation. The test was preformed as previously described (28). The mice were given a free exploration session, where they were briefly confined to the start chamber (for 30 seconds) and permitted access to the rest of the maze via the removal of a sliding door in the divider panel for a 7-minute trial. Entry into an arm opposite the previously chosen arm was defined as alternation, whereas entry into the previously visited arm was not. Thus, the alternation performance was operationally defined as the percentage of time the mice alternated (i.e., the number of alternations observed/the number of alternation attempts - 1). To control for odor cues, the T-maze apparatus was cleaned with $90 \%$ ethanol and dried after each trial.

\section{Immunohistochemistry and cell quantification}

The animals were deeply anesthetized and transcardially perfused with $4 \%$ paraformaldehyde in $100 \mathrm{mM}$ phosphate buffer, $\mathrm{pH}$ 7.4. Immunohistochemistry was performed on $30-\mu \mathrm{m}$ coronal sections as previously described (30), with the following primary antibodies: rat anti-BrdU (1:200; Abcam); mouse anti-NeuN (1:250; Millipore); mouse anti-GFAP (1:500; Sigma-Aldrich); rabbit anti-GFAP (1:100; Abcam); rabbit anti-Ki67 (1:200; Thermo Scientific); rabbit anti-Sox2 (1:200; Millipore); rabbit anti-DCX (1:1000; Abcam); rabbit anti-CR (1:1000; Millipore); and rabbit anti-AC3 (1:750; R\&D Systems). Fluorophoreconjugated (Alexa Fluor 488, Alexa Fluor 568, and Alexa Fluor 647) goat secondary antibodies (1:1000; Invitrogen) were used for detection. For Ki67 immunohistochemistry, antigen retrieval was performed with $10 \mathrm{mM}$ citrate buffer, $\mathrm{pH}$ 6.0,for 30 minutes at $80^{\circ} \mathrm{C}$. For BrdU immunohistochemistry, sections were pretreated with $2 \mathrm{~N} \mathrm{HCl}$ as previously described $(30,81)$. The sections were counterstained with the nuclear dye Hoechst-33342 (Sigma-Aldrich).

The stereological cell counting was performed in serial coronal sections (180 $\mu \mathrm{m}$ or $240 \mu \mathrm{m}$ apart) covering the complete rostro-caudal extension of the DG as previously described $(30,81)$. Fluorescence images were captured with a Nikon A1 confocal scanning microscope. For each section, confocal $z$-stack images ( $1 \mu \mathrm{m} z$-step size) covering the complete DG were acquired for DG reconstruction with NIS Element AR software (Nikon). Immunolabeled cells in the inner third of the granular cell layer (GCL) and the subgranular zone (SGZ, defined as a $10 \mu \mathrm{m}$ region below the GCL) were counted on the reconstructed images by an operator blinded to the experimental groups in accordance with the optical dissector principle (81). RGL precursors and amplifying precursors were identified by the expression of GFAP and Sox 2 and distinctive morphological features. RGL typically displayed a radial morphology, with the cell body located perpendicularly to the GCL and a single thin GFAP-positive process spanning the GCL (52). Amplifying progenitors were identified by the absence of radial morphology, with the cell body located parallel to the GCL. The few mature astrocytes (which were also positive for GFAP and Sox2) were excluded on the basis of their stellate morphology. The survival rates of the $\mathrm{BrdU}^{+}$cells and their progeny were calculated as the percentage of $\mathrm{BrdU}^{+}$cells observed at 4 weeks with respect to that observed at 24 hours after $\mathrm{BrdU}$ administration (\% survival $=\left[\mathrm{BrdU}^{+}\right.$cells at 4 weeks $/ \mathrm{BrdU}^{+}$cells at 24 hours] $\times 100$ ) as previously described (82). The neuronal cell density in the CA1 and CA3 hippocampal regions was stereologically evaluated on sections stained for $\mathrm{NeuN}$ and counterstained with Hoechst 33342 as previously described (30).

\section{ADNPCs}

NPCs were isolated from the DG of adult (6-8 weeks) WT and Ts65Dn mice and cultured as a monolayer on poly-D-lysine (PDL; Sigma-Aldrich) and laminin-coated (Roche) flasks in neurobasal medium containing B27, GlutaMAX, and penicillin-streptomycin solution (all from Invitrogen) supplemented with recombinant FGF-2 and EGF (PeproTech) as previously described (58). The cells were passaged at $70 \%-80 \%$ confluence using Accutase (PAA Laboratories) and replated at $10^{4}$ cells $/ \mathrm{cm}^{2}$.

The cells were transfected through electroporation using an Amaxa nucleofector device (Lonza). For the luciferase experiments, the cells were transfected with SuperTOPFlash (in which Firefly luciferase expression is driven through multiple TCF-binding sites upstream of a minimal TATA box; Addgene plasmid 12456) or SuperFOPFlash (in which the TCF-binding sites are mutated; Addgene plasmid 12457) plasmids (60), together with the pRL-TK vector expressing Renilla luciferase to normalize for transfection efficiency. Twenty-four hours after transfection, the ADNPCs were treated with $\mathrm{LiCl}(2 \mathrm{mM})$ or the corresponding vehicle $(2 \mathrm{mM} \mathrm{NaCl})$ or recombinant Wnt3a (10 ng/ml; PeproTech), and the luciferase activity was measured at 24 hours later using a Dual-Luciferase Assay Kit (Promega) according to the manufacturer's instructions. The results were expressed as the ratio of SuperTOPFlash over SuperFOPFlash normalized luciferase activity.

For the proliferation experiments, the cells were plated on PDL/laminincoated coverslips, and 48 hours later, the cells were pulse labeled for 2 hours with BrdU $(10 \mu \mathrm{M})$, fixed, and processed for BrdU immunofluorescence. The nuclei were counterstained with DAPI. For each coverslip, the percentage of $\mathrm{BrdU}^{+}$nuclei over the total nuclei was automatically determined using ImageJ software (http://rsbweb.nih.gov/ij/) and particles analysis plug-in (83). In experiments where the ADNPCs were transfected with the EdTC plasmid (61) expressing dominant-negative TCF4 and mCherry (Addgene plasmid 24310) or the corresponding control vector expressing mCherry alone, the cell proliferation was calculated as the percentage of $\mathrm{BrdU}^{+} \mathrm{Cherry}^{+}$double-labeled cells over total Cherry ${ }^{+}$cells.

\section{Electrophysiology}

Transverse or sagittal hippocampal slices $(400 \mu \mathrm{m})$ were prepared using a Microm HM 650V vibratome, transferred into a holding chamber containing oxygenated artificial cerebrospinal solution (ACSF: $119 \mathrm{mM} \mathrm{NaCl}$, $2.5 \mathrm{mM} \mathrm{KCl} 1.3 \mathrm{mM} \mathrm{MgSO}_{4}, 1 \mathrm{mM} \mathrm{NaH}_{2} \mathrm{PO}_{4}, 26 \mathrm{mM} \mathrm{NaHCO}_{3}, 2.5 \mathrm{mM}$ $\mathrm{CaCl}_{2}$, and $10 \mathrm{mM}$ glucose, $\mathrm{pH}$ 7.4), and incubated for at least 90 minutes at room temperature before recording. The slices were transferred into a recording chamber and continuously perfused with oxygenated ACSF $(2 \mathrm{ml} / \mathrm{min})$ at $31^{\circ} \mathrm{C} \pm 1^{\circ} \mathrm{C}$.

For the DG LTP recording, afferent fibers on the MPP were stimulated on the transverse slices using glass capillary electrodes (1-2 M $\Omega$ ), and the field excitatory post-synaptic potentials (fEPSPs) were recorded using glass capillary electrodes (4-5 M $\Omega$ ) filled with ACSF positioned in the medial molecular layer of the upper blade. Input/output (I/O) relationships were obtained after 20 minutes of stable recording, and the stimulation intensity that produced $70 \%$ of the maximal response was used for test pulses and tetanic stimulation. The paired-pulse ratio (PPR) analysis of the synaptic connectivity was assessed as previously reported (84). The PPR was calculated as the ratio between the fEPSP slopes in response to the second and the first stimulus, respectively. As previously reported, the paired-pulse stimulation of the MPP resulted in depression of the second stimulus (84). Baseline recordings were conducted with a frequency of 1 test stimulus every 30 seconds. Only slices showing fEPSPs of $1 \mathrm{mV}$ in amplitude or higher were selected for experiments. LTP was induced through a tetanic stimulation that consisted of four $100-\mathrm{Hz}$ trains of 0.5 seconds each repeated every 30 seconds. After induction, the responses were recorded every 30 seconds for at least 60 minutes. In some experiments, $100 \mu \mathrm{M}$ PTX (Sigma-Aldrich) or $1.5 \mu \mathrm{M}$ Ro25-6981 (Tocris), both dissolved in water, were applied at 20 minutes before LTP induction and maintained throughout the recording time.

For the CA3-CA1 LTP recording, Schaffer collateral fibers were stimulated on sagittal slices using bipolar tungsten electrodes $(0.5 \mathrm{M} \Omega)$, and 
the fEPSPs were recorded using glass capillary electrodes (4-5 M $\Omega$ ) filled with ACSF. Both electrodes were positioned in the stratum radiatum. Baseline recordings were conducted with a frequency of 1 test stimulus every 30 seconds. A stimulation intensity producing $70 \%$ of the maximal response was used for test pulses and tetanic stimulation. LTP was induced using $2 \theta$-burst stimulations (TBS: 10 trains of 4 pulses at $100 \mathrm{~Hz}$ and $200 \mathrm{~ms}$ apart) repeated after 30 seconds. After induction, the responses were recorded every 30 seconds for at least 60 minutes.

The data were $0.1-1000 \mathrm{~Hz}$ band-pass filtered and amplified using a DAM 80 amplifier (WPI), digitized at a sampling rate of $25 \mathrm{kHz}$ using a Digidata 1440A (Molecular Devices) running with Clampex software (Molecular Devices). The Clampfit software (Molecular Devices) was used for data analysis. The mean slope of fEPSPs recorded during the 10 minutes preceding LTP induction was considered as $100 \%$. The statistical significance of LTP induction within each group was determined using an unpaired Student's $t$ test between mean fEPSPs slopes recorded 0-5 minutes before and 40-45 minutes after LTP induction. The significant differences in PPR and I/O relationship for each interstimulus interval and stimulation intensity, respectively, were evaluated using 2-way ANOVA for genotype and treatment followed by Tukey's post hoc test.

\section{Western blotting}

Hippocampal tissue was sonicated in lysis buffer $(150 \mathrm{mM} \mathrm{NaCl}, 1 \mathrm{mM}$ EGTA, $0.5 \%$ Triton $\mathrm{X}-100,1 \%$ SDS, $10 \mathrm{mM}$ Tris, $\mathrm{pH}$ 7.4) containing $1 \mathrm{mM}$ PMSF, $10 \mathrm{mM} \mathrm{NaF}$ and $1 \%(\mathrm{v} / \mathrm{v})$ protease and phosphatase inhibitor cocktails (Sigma-Aldrich). The samples were clarified through centrifugation at $20,000 \mathrm{~g}$, and the protein concentration was determined using the BCA kit (Pierce). Equal amounts of protein were run on $10 \%$ Criterion-XT gels (BioRad Laboratories) and transferred onto nitrocellulose membranes (GE Healthcare). Membranes were probed with mouse anti-active $\beta$-catenin (clone 8E7; Millipore) $(55,56)$ and rabbit anti-total $\beta$-catenin (Cell Signaling Technologies) antibodies followed by fluorophore-conjugated (antimouse-Cy3 and anti-rabbit-Cy5) goat secondary antibodies (GE Healthcare). The signals were acquired with a Typhoon fluorescent scanner (GE Healthcare), and the band intensities were quantified using ImageQuant software (GE Healthcare).

\section{Statistics}

The results are presented as the means \pm SEM. The statistical analysis was performed using SigmaStat (Systat) or Prism (GraphPad) software. Where appropriate, the statistical significance was evaluated using a 2-tailed unpaired $t$ test and a 1-way or 2-way ANOVA followed by all pairwise Tukey or Bonferroni post hoc tests. $P<0.05$ was considered significant.

\section{Study approval}

A veterinarian was employed to maintain animal health and comfort. The mice were housed in filtered cages in a temperature-controlled room with a 12-hour light/12-hour dark cycle with ad libitum access to water and food. All animal experiments were performed in accordance with the guidelines established by the European Community Council Directive 2010/63/EU of September 22, 2010, and were approved through the Italian Ministry of Health and the Italian Institute of Technology (IIT) Ethical Committee.

\section{Acknowledgments}

The authors would like to thank Simone Nitti (IIT Nanochemistry Department) for the ICP-MS determination of serum and brain lithium concentrations and R. Nusse (Stanford University, Stanford, California, USA) and R.T. Moon (University of Washington, Seattle, Washington, USA) for sharing plasmids. The authors would also like to thank to L. Cancedda and A. Dityatev (IIT) for critically reviewing the manuscript. This work was funded through a grant from the Fondation Jerôme Lejeune (France) to A. Contestabile and the Italian Institute of Technology.

Received for publication May 11, 2012, and accepted in revised form October 4, 2012.

Address correspondence to: Andrea Contestabile or Laura Gasparini, Department of Neuroscience and Brain Technologies, Italian Institute of Technology (IIT), Via Morego 30, 16163 Genova, Italy. Phone: 39.010.71781785; Fax: 39.010.71781230; E-mail: andrea. contestabile@iit.it (A. Contestabile).Phone: 39.010.71781519; Fax: 39.010.71781230; laura.gasparini@iit.it (L. Gasparini).
1. Snyder JS, Kee N, Wojtowicz JM. Effects of adult neurogenesis on synaptic plasticity in the rat dentate gyrus. J Neurophysiol. 2001;85(6):2423-2431.

2. Ge S, Yang C, Hsu K, Ming G, Song H. A critical period for enhanced synaptic plasticity in newly generated neurons of the adult brain. Neuron. 2007; 54(4):559-566.

3. Schmidt-Hieber C, Jonas P, Bischofberger P. Enhanced synaptic plasticity in newly generated granule cells of the adult hippocampus. Nature. 2004;429(6988):184-187.

4. Mongiat LA, Esposito MS, Lombardi G, Schinder AF. Reliable activation of immature neurons in the adult hippocampus. PloS One. 2009;4(4):e5320.

5. Wang S, Scott BW, Wojtowicz JM. Heterogenous properties of dentate granule neurons in the adult rat. J Neurobiol. 2000;42(2):248-257.

6. Ge S, Sailor KA, Ming G, Song H. Synaptic integration and plasticity of new neurons in the adult hippocampus. J Physiol. 2008;586(16):3759-3765.

7. Saxe MD, et al. Ablation of hippocampal neurogenesis impairs contextual fear conditioning and synaptic plasticity in the dentate gyrus. PNAS. 2006; 103(46):17501-17506.

8. Marín-Burgin A, Mongiat LA, Pardi MB, Schinder AF. Unique processing during a period of high excitation/inhibition balance in adult-born neurons. Science. 2012;335(6073):1238-1242.

9. Imayoshi I, et al. Roles of continuous neurogenesis in the structural and functional integrity of the adult forebrain. Nat Neurosci. 2008;11(10):1153-1161.

10. Winocur G, Wojtowicz JM, Sekeres M, Snyder JS, Wang S. Inhibition of neurogenesis interferes with hippocampus-dependent memory function. Hippocampus. 2006;16(3):296-304.

11. Garthe A, Behr J, Kempermann G. Adult-generated hippocampal neurons allow the flexible use of spatially precise learning strategies. PloS One. 2009; 4(5):e5464

12. Sahay A, et al. Increasing adult hippocampal neurogenesis is sufficient to improve pattern separation. Nature. 2011;472(7344):466-470.

13. Clelland CD, et al. A functional role for adult hippocampal neurogenesis in spatial pattern separation. Science. 2009;325(5937):210-213.

14. Crews L, et al. Increased BMP6 levels in the brains of Alzheimer's disease patients and APP transgenic mice are accompanied by impaired neurogenesis. JNeurosci. 2010;30(37):12252-12262.

15. Hamilton LK, Aumont A, Julien C, Vadnais A, Calon F, Fernandes KJ. Widespread deficits in adult neurogenesis precede plaque and tangle formation in the $3 \times \mathrm{Tg}$ mouse model of Alzheimer's disease. Eur J Neurosci. 2010;32(6):905-920.

16. Garza JC, Guo M, Zhang W, Lu XY. Leptin restores adult hippocampal neurogenesis in a chronic unpredictable stress model of depression and reverses glucocorticoid-induced inhibition of GSK-3 $\beta / \beta$-catenin signaling. Mol Psychiatry. 2012; 17(8):790-808.
17. Snyder JS, Soumier A, Brewer M, Pickel J, Cameron HA. Adult hippocampal neurogenesis buffers stress responses and depressive behaviour. Nature. 2011;476(7361):458-461.

18. Mao Y, et al. Disrupted in schizophrenia 1 regulates neuronal progenitor proliferation via modulation of GSK3beta/beta-catenin signaling. Cell. 2009;136(6):1017-1031.

19. Guo W, et al. Ablation of Fmrp in adult neural stem cells disrupts hippocampus-dependent learning. Nat Med. 2011;17(5):559-565.

20. Ishihara $\mathrm{K}$, et al. Enlarged brain ventricles and impaired neurogenesis in the Ts1Cje and Ts2Cje mouse models of Down syndrome. Cereb Cortex. 2010;20(5):1131-1143.

21. Coras R, et al. Low proliferation and differentiation capacities of adult hippocampal stem cells correlate with memory dysfunction in humans. Brain. 2010;133(11):3359-3372.

22. Kempermann G, Kuhn HG, Gage FH. More hippocampal neurons in adult mice living in an enriched environment. Nature. 1997; 386(6624):493-495.

23. Santarelli L, et al. Requirement of hippocampal neurogenesis for the behavioral effects of antidepressants. Science. 2003;301(5634):805-809.

24. Contestabile A, Benfenati F, Gasparini L. Communication breaks-Down: From neurodevelopment defects to cognitive disabilities in Down syndrome. Prog Neurobiol. 2010;91(1):1-22. 
25. Pennington BF, Moon J, Edgin J, Stedron J, Nadel L. The neuropsychology of Down syndrome: evidence for hippocampal dysfunction. Child Dev. 2003; 74(1):75-93.

26. Rowe J, Lavender A, Turk V. Cognitive executive function in Down's syndrome. Br JClin Psychol. 2006; 45(pt 1):5-17.

27. Ellis NR, Woodley-Zanthos P, Dulaney CL. Memory for spatial location in children, adults, and mentally retarded persons. Am J Ment Retard. 1989; 93(5):521-526.

28. Fernandez F, et al. Pharmacotherapy for cognitive impairment in a mouse model of Down syndrome. Nat Neurosci. 2007;10(4):411-413.

29. Kleschevnikov AM, Belichenko PV, Villar AJ, Epstein CJ, Malenka RC, Mobley WC. Hippocampal longterm potentiation suppressed by increased inhibition in the Ts65Dn mouse, a genetic model of Down syndrome. J Neurosci. 2004;24(37):8153-8160.

30. Contestabile A, et al. Cell cycle alteration and decreased cell proliferation in the hippocampal dentate gyrus and in the neocortical germinal matrix of fetuses with Down syndrome and in Ts65Dn mice. Hippocampus. 2007;17(8):665-678.

31. Chakrabarti L, et al. Olig1 and Olig2 triplication causes developmental brain defects in Down syndrome. Nat Neurosci. 2010;13(8):927-934.

32. Chakrabarti L, Galdzicki Z, Haydar TF. Defects in embryonic neurogenesis and initial synapse formation in the forebrain of the Ts65Dn mouse model of Down syndrome. J Neurosci. 2007; 27(43):11483-11495.

33. Roper RJ, Baxter LL, Saran NG, Klinedinst DK, Beachy PA, Reeves RH. Defective cerebellar response to mitogenic Hedgehog signaling in Down syndrome mice. Proc Natl Acad Sci US A. 2006; 103(5):1452-1456.

34. Reeves RH, et al. A mouse model for Down syndrome exhibits learning and behaviour deficits. Nat Genet. 1995;11(2):177-184.

35. Clark S, Schwalbe J, Stasko MR, Yarowsky PJ, Costa AC. Fluoxetine rescues deficient neurogenesis in hippocampus of the Ts65Dn mouse model for Down syndrome. Exp Neurol. 2006;200(1):256-261.

36. Bianchi P, Ciani E, Contestabile A, Guidi S, Bartesaghi R. Lithium restores neurogenesis in the subventricular zone of the Ts65Dn mouse, a model for Down syndrome. Brain Pathology. 2009;20(1):106-118.

37. Chen G, Rajkowska G, Du F, Seraji-Bozorgzad N, Manji HK. Enhancement of hippocampal neurogenesis by lithium. J Neurochem. 2000;75(4):1729-1734.

38. Wexler EM, Geschwind DH, Palmer TD. Lithium regulates adult hippocampal progenitor development through canonical Wnt pathway activation. Mol Psychiatry. 2008;13(3):285-292.

39. Lie DC, et al. Wnt signalling regulates adult hippocampal neurogenesis. Nature. 2005; 437(7063):1370-1375.

40. Brandt MD, et al. Transient calretinin expression defines early postmitotic step of neuronal differentiation in adult hippocampal neurogenesis of mice. Mol Cell Neurosci. 2003;24(3):603-613.

41. Pearce JM, Lyon M, Komoroski RA. Localized ${ }^{7} \mathrm{Li} \mathrm{MR}$ spectroscopy: in vivo brain and serum concentrations in the rat. Magn Reson Med. 2004; 52(5):1087-1092.

42. Stone SSD, et al. Stimulation of entorhinal cortex promotes adult neurogenesis and facilitates spatial memory. J Neurosci. 2011;31(38):13469-13484.

43. Costa CSA, Scott-McKean JJ, Stasko MR. Acute injections of the NMDA receptor antagonist memantine rescue performance deficits of the Ts65Dn mouse model of Down syndrome on a fear conditioning test. Neuropsychopharmacology. 2007; 33(7):1624-1632

44. Jessberger S, et al. Dentate gyrus-specific knockdown of adult neurogenesis impairs spatial and object recognition memory in adult rats. Learn
Mem. 2009;16(2):147-154.

45. Wojtowicz JM, Askew ML, Winocur G. The effects of running and of inhibiting adult neurogenesis on learning and memory in rats. Eur J Neurosci. 2008; 27(6):1494-1502.

46. Drew MR, Denny CA, Hen R. Arrest of adult hippocampal neurogenesis in mice impairs singlebut not multiple-trial contextual fear conditioning. Behav Neurosci. 2010;124(4):446-454.

47. Mustafa S, Walker A, Bennett G, Wigmore PM. 5-Fluorouracil chemotherapy affects spatial working memory and newborn neurons in the adult rat hippocampus. Eur J Neurosci. 2008;28(2):223-230.

48. Bruel-Jungerman E, Laroche S, Rampon C. New neurons in the dentate gyrus are involved in the expression of enhanced long-term memory following environmental enrichment. EurJ Neurosci. 2005; 21(2):513-521.

49. O’Doherty A, et al. An aneuploid mouse strain carrying human chromosome 21 with Down syndrome phenotypes. Science. 2005;309(5743):2033-2037.

50. Lalonde R. The neurobiological basis of spontaneous alternation. Neurosci Biobehav Rev. 2002; 26(1):91-104

51. Hernández-Rabaza $V$, et al. Inhibition of adult hippocampal neurogenesis disrupts contextual learning but spares spatial working memory, longterm conditional rule retention and spatial reversal. Neurosci. 2009;159(1):59-68.

52. Liu Y, Namba T, Liu J, Suzuki R, Shioda S, Seki T. Glial fibrillary acidic protein-expressing neural progenitors give rise to immature neurons via early intermediate progenitors expressing both glial fibrillary acidic protein and neuronal markers in the adult hippocampus. Neurosci. 2010;166(1):241-251.

53. Aasebo IEJ, Blankvoort S, Tashiro A. Critical maturational period of new neurons in adult dentate gyrus for their involvement in memory formation. Eur J Neurosci. 2011;33(6):1094-1100.

54 . O'Brien WT, et al. Glycogen synthase kinase-3 $\beta$ haploinsufficiency mimics the behavioral and molecular effects of lithium. J Neuroscience. 2004; 24(30):6791-6798.

55. van Noort M, Meeldijk J, van der Zee R, Destree O, Clevers H. Wnt signaling controls the phosphorylation status of beta-catenin. J Biol Chem. 2002; 277(20):17901-17905.

56. van Noort M, Weerkamp F, Clevers HC, Staal FJ. Wnt signaling and phosphorylation status of betacatenin: importance of the correct antibody tools. Blood. 2007;110(7):2778-2779.

57. Gingrich JC, Davis DR, Nguyen Q. Multiplex detection and quantitation of proteins on western blots using fluorescent probes. Biotechniques. 2000; 29(3):636-642.

58. Babu H, Cheung G, Kettenmann H, Palmer TD, Kempermann G. Enriched monolayer precursor cell cultures from micro-dissected adult mouse dentate gyrus yield functional granule cell-like neurons. PLoS One. 2007;2(4):e388.

59. Mosimann C, Hausmann G, Basler K. Beta-catenin hits chromatin: regulation of Wnt target gene activation. Nat Rev Mol Cell Biol. 2009;10(4):276-286.

60. Veeman MT, Slusarski DC, Kaykas A, Louie SH, Moon RT. Zebrafish prickle, a modulator of noncanonical Wnt/Fz signaling, regulates gastrulation movements. Curr Biol. 2003;13(8):680-685.

61. Fuerer C, Nusse R. Lentiviral vectors to probe and manipulate the Wnt signaling pathway. PLoS One. 2010;5(2):e9370.

62. Ge S, Goh ELK, Sailor KA, Kitabatake Y, Ming G, Song H. GABA regulates synaptic integration of newly generated neurons in the adult brain. Nature. 2006;439(7076):589-593.

63. Snyder JS, Hong NS, McDonald RJ, Wojtowicz JM. A role for adult neurogenesis in spatial long-term memory. Neuroscience. 2005;130(4):843-852.

64. Huang W, et al. Brain myo-inositol level is elevated in Ts65Dn mouse and reduced after lithium treatment. Neuroreport. 2000;11(3):445-448

65. Bateman RJ, et al. Clinical and biomarker changes in dominantly inherited Alzheimer's disease. N Engl J Med. 2012;367(9):795-804.

66. Holtzman DM, Goate A, Kelly J, Sperling R. Mapping the road forward in Alzheimer's disease. Sci Transl Med. 2011;3(114):114ps148.

67. Hanson JE, Blank M, Valenzuela RA, Garner CC, Madison DV. The functional nature of synaptic circuitry is altered in area CA3 of the hippocampus in a mouse model of Down's syndrome. JPhysiol. 2007; 579(pt 1):53-67.

68. Tozuka Y, Fukuda S, Namba T, Seki T, Hisatsune T. GABAergic excitation promotes neuronal differentiation in adult hippocampal progenitor cells. Neuron. 2005;47(6):803-815.

69. Ahn S, Joyner AL. In vivo analysis of quiescent adult neural stem cells responding to Sonic hedgehog. Nature. 2005;437(7060):894-897.

70. Fernandez-Martinez J, Vela EM, Tora-Ponsioen M, Ocana $\mathrm{OH}$, Nieto MA, Galceran J. Attenuation of Notch signalling by the Down syndrome-associated kinase DYRK1A.J Cell Sci. 2009;122(Pt 10):1574-1583.

71. Ables JL, et al. Notch 1 is required for maintenance of the reservoir of adult hippocampal stem cells. J Neurosci. 2010;30(31):10484-10492.

72. Breunig JJ, Silbereis J, Vaccarino FM, Sestan S, Rakic P. Notch regulates cell fate and dendrite morphologyof newborn neurons in the postnatal dentate gyrus. Proc Natl Acad Sci U S A. 2007; 104(51):20558-20563.

73. Mangan PA. Spatial Memory Abilities And Abnormal Development Of The Hippocampal Formation In Down Syndrome [dissertation]. Tucson, Arizona, USA: University of Arizona; 1992.

74. Carlesimo GA, Marotta L, Vicari S. Long-term memory in mental retardation: evidence for a specific impairment in subjects with Down's syndrome. Neuropsychologia. 1997;35(1):71-79.

75. Grandjean EM, Aubry JM. Lithium: updated human knowledge using an evidence-based approach. Part II: Clinical pharmacology and therapeutic monitoring. CNS Drugs. 2009;23:331-349.

76. Dolk H, et al. Trends and geographic inequalities in the prevalence of Down syndrome in Europe, 1980-1999. Rev Epidemiol Sante Publique. 2005; 53 spec no 2:2S87-2S95.

77. Shin M, Besser L, Kucik JE, Lu C, Siffel C, Correa A. Prevalence of Down syndrome among children and adolescents in 10 regions of the United States. Pediatrics. 2009;124(6):1565-1571.

78. Bittles AH, Bower C, Hussain R, Glasson EJ. The four ages of Down syndrome. Eur J Public Health. 2006; 17(2):221-225.

79. Bittles AH, Glasson EJ. Clinical, social, and ethical implications of changing life expectancy in Down syndrome. Dev Med Child Neurol. 2004;46(4):282-286.

80. Hewitt CA, Carmichael CL, Wilkins EJ, Cannon PZF, Pritchard MA, Scott HS. Multiplex ligationdependent probe amplification (MLPA) genotyping assay for mouse models of down syndrome. Front Biosci. 2007;12:3010-3016.

81. Kempermann G, Gast D, Kronenberg G, Yamaguchi M, Gage FH. Early determination and long-term persistence of adult-generated new neurons in the hippocampus of mice. Development. 2003;130(2):391-399.

82. van Praag H, Kempermann G, Gage FH. Running increases cell proliferation and neurogenesis in the adult mouse dentate gyrus. Nature. 1999;2(3):266-270.

83. Drury JA, Nik H, van Oppenraaij RH, Tang AW, Turner MA, Quenby S. Endometrial cell counts in recurrent miscarriage: a comparison of counting methods. Histopathology. 2011;59(6):1156-1162.

84. Colino A, Malenka RT. Mechanisms underlying induction of long-term potentiation in rat medial and lateral perforant paths in vitro. J Neurophysiol. 1993;69(4):1150-1159. 